\title{
Technological Diversification and Smart Specialization: \\ the role of cooperation
}

\author{
Artur Santoalha*
}

September 2018

\begin{abstract}
Smart Specialization is closely associated with the concept of diversification. For better understanding of Smart Specialization, this article examines one little-explored explanatory factor of technological diversification: cooperation within and between regions. Using OECD REGPAT data on co-applications for patents, the empirical analysis investigates the role of cooperation between organizations on technological diversification in 226 European regions over ten five-year periods, 2000-2013. Cooperation within and between regions emerges as an important a determinant of regional diversification, but both forms of cooperation should evolve hand in hand - singly, each form may prove ineffective for boosting regional diversification.
\end{abstract}

Key words: smart specialization, diversification, patents, European regions, cooperation JEL codes: O31 O38 R11

\footnotetext{
* University of Oslo - Centre for Technology, Innovation and Culture - P.O. box 1108, Blindern 0317 Oslo Email address - artur.santoalha@tik.uio.no
} 


\section{Technological Diversification and Smart Specialization: \\ the role of cooperation}

\section{Introduction}

Smart specialization (S3) is a prominent topic in the EU regional policy landscape. However, empirical evidence underpinning the arguments is inadequate (Foray et al., 2011). As S3 has been increasingly associated with diversification, or 'diversified specialization' (Asheim et al., 2016), regional diversification offers a relevant framework for studying S3 processes in European regions (Balland et al., 2018).

Regional diversification and its determinants is a new strand of research in the field of evolutionary economic geography. Neffke et al. (2011) studied the role of relatedness in the entry of new industrial specializations in 70 Swedish regions. Since then, the role of relatedness on diversification at subnational level has been extensively discussed (Boschma et al., 2013; Boschma et al., 2015; Essletzbichler, 2015, Xiao et al., 2018). Cortinovis et al. (2017) and Balland et al. (2018) have investigated other possible explanations for diversification. All these studies, using entry models, analyse the determinants that contribute to the entry of a new industrial/technological variety in a given region. This is useful for identifying factors relevant for exploring new varieties. However, such methodology provides little information on the extent to which regions are actually diversifying, and does not explain differentiated regional diversification behaviours. How good are various regions at diversifying? How can they improve it? How differentiated should regions behave, taking into account their features?

All these questions are important, as the overall capacity of a given region to diversify into new technologies may influence its innovative, industrial and economic capacity. Moreover, these questions are relevant for understanding how successful a given region is in achieving diversification within the scope of an S3 process. This article focuses on a specific aspect of 
diversification relevant to S3: cooperation. More specifically, this article investigates whether regional cooperation between organizations, as measured by co-applications for patents, contributes to regional diversification. Moreover, it distinguishes between intra-regional cooperation (cooperation deriving from collaborative projects where all involved parts belong to the same region) and inter-regional cooperation (cooperation between partners that belong to different regions).

Although the impact of regional cooperation on innovation has been extensively discussed (De Noni et al., 2017; Broekel et al., 2015; Broekel, 2012), its impact on regional diversification has never been empirically tested. Cooperation constitutes a cornerstone of S3: new specializations should be the outcome of collaborative efforts involving several regional actors. Further, in S3, regions should cooperate with other regions, to take advantage of possible similarities and complementarities (Foray et al., 2012). Empirical evidence should underpin these principles, but such studies have been lacking.

This article has a twofold aim: to shed light on the role of cooperation on the technological diversification of European regions; and then discuss its importance in terms of S3. Using the OECD REGPAT database, it proposes a regional diversification index for measuring technological diversification in 226 European regions over 10 periods of 5 years each, 20002013.

In section 2, this article argues that processes of regional diversification may capture the concept of S3, and therefore it proposes to study the latter by the former. Section 3 discusses the relevance of cooperation to regional diversification. Section 4 describes the data and the indicators used in this research. The empirical methodology is presented in section 5; results are discussed in section 6 , followed by conclusions in section 7 . 


\section{Smart Specialization as a diversification process}

S3 poses three distinct challenges: conceptual, operational and political (Morgan, 2013). The first concerns the meaning of the concept; the other two involve translating it into a strategy and applying it to a given territory. The concept, as initially defined by Foray et al. (2009), is exclusively based on industrial and science policy: S3 would support those technologies and science domains with the highest impact on the most relevant economic sectors in each economy. Although the authors do not approach the topic as a regional innovation policy, S3 has quickly acquired a regional innovation systems logic (McCann and Ortega-Argiles, 2011). McCann and Ortega-Argiles were the first to propose this transition, in a working paper (McCann and Ortega-Argiles, 2011), and later in an academic article (McCann and OrtegaArgiles, 2015). In order to translate the non-spatial and sectoral idea of S3 into a regional innovation policy, these authors argue that an essential aspect (jointly with embeddedness and connectivity) is to approach S3 as a process of related diversification. In light of this, and among other aspects, S3 defends the prioritization of regional capabilities (skills, technologies, etc) that are new to the region, as well as related to the existing regional industrial or technological structures.

This has heavily influenced the S3 literature, which often describes S3 as a process of related diversification (Boschma \& Giannelle, 2014; Foray, 2013). However, Foray et al. (2012) admit that the structural change required in any S3 process may derive from either radical innovation or innovation through related diversification; and Asheim et al. (2016) note that S3 may lead to related or unrelated diversification, depending on the regional strategy adopted. Moreover, Fagerberg \& Shrolec (2016) are sceptical to a S3 strategy based solely on pursuing a related diversification path. However, several authors agree that S3 is about diversification. The idea of diversification into new specializations (where each region has greater potential than others) 
is at the heart of the concept of S3. This paper adopts this view as the lowest common denominator found in the S3 literature.

Today the meaning and logic of S3 are no longer seen as a major challenge. However, as the policy and its design depend on how policymakers interpret the concept, it is necessarily subjective and difficult to approach. This study focuses exclusively on the concept of S3 as described above. Using regional data on patents (Rigby, 2015), employment (Xiao et al., 2018) or traded goods (Boschma et al., 2013), it is possible to trace the diversification paths of regions, identifying in which technologies or industries new specializations emerge. However, knowledge about such diversification paths does not allow determination of whether such new areas of specialization have greater regional potential.

New specializations reflect micro-level decisions of regional actors to explore, develop and accumulate certain capacities, and not others, in specific areas of activity. This can be the outcome of a process of self-discovery (entrepreneurial discovery process: EDP), which may occur spontaneously in sound regional innovation systems (Capello \& Kroll, 2016). The study of regional diversification paths does not necessarily neglect the importance of the S3 basilar principle of EDP, and can offer at least an approximation of the priorities each region would define at a given time point.

Moreover, although the emergence of S3 as a policy concept is fairly new (gaining prominence in Europe only after 2010), the underlying reasoning is not: it is based on the capacity of regional actors to cooperate and identify new regional priorities (see Foray et al., 2011; Morgan, 2016). Thus, it seems reasonable to go back before 2010 and evaluate European regions as regards diversification, to understand the determinants and shed light on the concept of S3. This approach has three main advantages. First, the analysis can be extended to periods before the emergence of S3 as a regional innovation policy in Europe. Otherwise, the short time-span since the establishment of S3 normally constitutes a limitation to studying the topic. Second, it 
circumvents the lack of centralized information on the S3 strategies of European regions. Third, it overcomes the problem of the subjectivity underlying the interpretation of the policy concept and strategy design - at the cost of lack of precision and all the limitations underlying the use of specific databases for such purposes. As the present study uses essentially data on patents, only regional technological diversification can be investigated here. While acknowledging the limitations entailed in using patent data (OECD, 2009), the article holds that this analysis can improve our understanding of the technological aspects of S3.

\section{Cooperation, diversification and $\mathrm{S3}$}

'By engaging in greater exchange not only individuals and territories become more innovative or creative, they also achieve a significant leap with the adoption of best practices' (RodriguezPose \& Crescenzi, 2008, p. 373). This sentence summarizes well the importance of cooperation for regional development strategies in general, and S3 is no exception. As pointed out by Boschma \& Giannelle (2014), processes of knowledge transfer such as entrepreneurship, labour mobility and collaborative networks constitute an important aspect of S3, as these mechanisms may foster regional diversification. Focusing exclusively on collaborative networks, existing empirical evidence supports that inter-organizational collaboration generally fosters innovative performance in firms(Faems et al, 2005; Boschma \& ter Wal, 2007; Fitjar \& Rodríguez-Pose, 2013).

At the regional level, there are still few empirical studies of the role of collaboration intensity as regards innovation performance. However, here it is important to distinguish between intraand inter-regional collaboration (Broekel 2012; Broekel et al., 2015; Sun \& Cao, 2015; Sun, 2016; De Noni et al., 2017). Both forms of cooperation foster the flow of knowledge and ideas at different geographical levels: either within or between regions (De Noni et al., 2017). In principle, cooperation within and between regions is likely to be relevant to diversification and S3, although their importance in these processes may be differentiated. While intra-regional 
networks may be important in connecting different regional actors and bringing new knowledge to the organizations involved, inter-regional collaboration may also do so, by introducing into the regions resources not previously available there (Sun, 2016; De Noni et al., 2017). Overall, this contributes to the recombination of knowledge held by different actors, leading to innovation through the creation of new ideas. The theoretical arguments and specific mechanisms that underpin such processes range from productivity and efficiency reasons, to spillovers and agglomeration effects (Nooteboom, 2000; Uyarra et al., 2014).

Sound regional innovation systems rely on 'actors that generate novelty by drawing on local and external knowledge' (Graf, 2011, p. 173). Thus, it would appear possible to assume both forms of cooperation should have a positive impact on regional diversification. However, the impact of collaboration may depend on several aspects, ranging from the regional environment to features of the interacting agents. For instance, Narula (2000) argues that Norwegian innovation system suffers from technological lock-in. Due to their political and economic importance, large Norwegian firms that operate in mature resource-intensive sectors can influence and shape the system according to their needs (Narula, 2000). In such innovation systems, any cooperation efforts are likely to constitute self-reinforcing mechanisms that preserve the development of existing technologies and hamper the growth of new ones. Boschma (2005) notes how, although a minimum degree of proximity between different agents is desirable to foster knowledge transmission, too much proximity may prove pernicious. It can lock-in creativity and innovation, obstructing diversification (see also Boschma \& Iammarino, 2009; Broekel \& Boschma, 2012). These are just two arguments that illustrate cases where the impact of cooperation on diversification may not be positive. Therefore, an important caveat is that processes of collaboration do not always foster new knowledge and ideas (Fritsch, 2003; Fritsch, 2004; Broekel, 2012). 
Another important aspect to consider is the role of regional variety in moderating the impact of cooperation on knowledge creation. With intra-regional cooperation, this aspect relates to the possible existence of Jacobian externalities; in more diversified regions, there are greater possibilities to recombine ideas than in highly specialized ones. Although that view ignores the possible existence of Marshallian externalities, the currently prevalent perspective supports the advantages underlying diversity for knowledge creation (De Noni et al., 2017). According to Grillitsch (2016), the greater the diversity of regional actors, more diversification opportunities will the region be able to explore: therefore, a more diverse and integrated (cooperative) environment creates conditions favourable to diversification, structural change and a successful S3 process. Similarly, the impact on innovation of the absorption of external knowledge from other regions may also depend on the existing regional variety. It is well known that developed economies have a more diverse and rich technological environment than those at earlier stages of development (Petralia, 2017). It is also likely that regions at later stages of their economic development are richer and more diverse, in terms of technologies but also economic activities and other institutions. Thus, as regions become more developed, cooperation should be more effective in fostering regional diversification.

A balance between both forms of cooperation has a positive impact on regional knowledge production (Bathelt et al., 2004; Broekel 2012 ; Sun and Cao, 2015; De Noni et al., 2017) indicating that each type of cooperation benefits from the other. On the one hand, collaboration within regions in the absence of external knowledge may lead to lock-in scenarios, especially in less diversified regions. In some cases, existence of inter-regional cooperation is essential, to introduce additional diversification opportunities. On the other hand, such collaboration should be well integrated in a regional innovation system. Otherwise, the imported knowledge will not flow within the region, limiting the opportunities for regional recombination. Cooperation within and between regions should evolve hand in hand, so that each form of cooperation can 
effectively foster diversification. To some extent, Asheim et al. (2016) illustrate this in their case study on the S3 strategy of Møre og Romsdal, in Norway. On the one hand, the limited regional diversity in this territory is counterbalanced by drawing on expertise and knowledge outside of the region. On the other hand, thanks to collaboration among various types of stakeholders, the region has had outstanding opportunities for (related) diversification.

\section{Data}

Data are drawn from the OECD REGPAT database, Eurostat regional statistics and EC DG Regio. The OECD REGPAT database ${ }^{1}$ is the most used dataset, including information on patent applications to the EPO (European Patent Office) as well as the PCT (Patent Co-operation Treaty). All variables elaborated using data on patent applications rely on it. ${ }^{2}$ The data are for the years 2000-2013; the main variables of interest cover all five-year periods in this interval. Thus, the sample includes observations spread across ten periods, from 2000-2004 up to 20092013. ${ }^{3}$ Most of other variables are from the beginning of each five-year period.

The unit of analysis is European regions (NUTS 2), ${ }^{4}$ the initial purpose has been to work with data for territories of the EU28 plus the EFTA countries. However, due to lack of available data, and to keep the panel balanced, it was not possible to include all regions and countries in the sample. The resultant sample consists of 226 regions followed for each of the ten periods considered, and distributed across 27 countries $^{5}$ : a total of 2260 observations.

\subsection{Construction of variables}

\subsubsection{Technological Specializations}

\footnotetext{
${ }^{1}$ February 2016 version

${ }^{2}$ Patent applications are accounted for by the fractional counting method and regionalized by applicants' address (Maraut et al. 2008).

${ }^{3}$ Following Xiao et al. (2018), this article uses overlapping periods to maximize the number of available observations. However, this is not problematic (see coefficient of the lagged dependent variable in table 3 ).

${ }^{4} 2010$ classification

${ }^{5}$ EU28 except Slovenia
} 
In line with other scholars, regional technological diversification is measured by the emergence of new technological specializations in regions. Therefore, the first step to compute diversification requires defining the concept of specialization. This begins with computing the Revealed Comparative Advantage (RCA). For each year and region in the sample, the RCA for each individual technological field (IPC subclass) is computed according to the following formula:

$\mathrm{RCA}_{\mathrm{izt}}=\frac{\text { PATizt }}{\sum_{z=1}^{n} \text { PATizt }} / \frac{\sum_{i=1}^{m} \text { PATizt }}{\sum_{i=1}^{m} \sum_{z=1}^{n} \text { PATizt }}$

where $\mathrm{RCA}_{\mathrm{izt}}$ represents the Revealed Comparative Advantage of region i, in technology $\mathrm{z}$, at year $\mathrm{t}$, while $\mathrm{PAT}_{\mathrm{izt}}$ is the number of patent applications attributed to technological field $\mathrm{z}$ in region $\mathrm{i}$ and year $\mathrm{t}$. This indicator, for year $\mathrm{t}$ and region $\mathrm{i}$, compares the regional share of patents involving a given technology $\mathrm{z}$ with the share of patents for the same technology computed for all other regions at time $\mathrm{t}$ - showing whether a given region, at a given time point, is relatively more or less specialized in technology $\mathrm{z}$ than all other regions together. If for a given year, region, and technology, the indicator is greater than 1 , that means region $\mathrm{i}$, in year $\mathrm{t}$, has a specialization in technology z.

In this this study, technological domains are proxied by IPC technological classes. This classification system is the most common when EPO patent applications are used. Regarding the level of aggregation, the adoption of 122 IPC classes (technological domains aggregated at 3-digit level) is intended to match the level of analysis that is relevant to S3: mid-grained granularity - an intermediate level of aggregation (Foray, 2013). Although the technological diversification literature may operate with higher levels of disaggregation (Boschma et al. 2015; 
Rigby, 2015), the choice of IPC classes is in line with Balland et al. (2018), who also propose a technological diversification framework for studying S3 processes in European regions. ${ }^{6}$

\subsubsection{Diversification indicators}

This work evaluates diversification in five-year periods, which is a sufficiently long period for observing a substantial evolution in terms of technological diversification in most regions. This follows the spirit of other regional diversification studies (Balland et al, 2018; Cortinovis et al., 2017, Xiao et al., 2018). The first possibility to measure diversification is to consider it as the total number of new specializations emerging in region $\mathrm{i}$ between $\mathrm{t}$ and $\mathrm{t}+4$ :

$\mathrm{X}_{\mathrm{it}, \mathrm{t}+4}=\sum_{z=1}^{n} \mathrm{~S}_{i t+4}$

such that:

$\mathrm{S}_{\mathrm{izt}+4}=1$ if $\mathrm{RCA}_{\mathrm{izt}} \leq 1 \wedge \mathrm{RCA}_{\mathrm{izt}+4}>1$

$\mathrm{S}_{\mathrm{izt}+4}=0$ if $\left(\mathrm{RCA}_{\mathrm{izt}}>1 \wedge \mathrm{RCA}_{\mathrm{izt}+4}>1\right) \vee \mathrm{RCA}_{\mathrm{izt}+4} \leq 1$

where $S_{\mathrm{izt}+4}$ is a dummy variable that takes the value 1 if region $\mathrm{i}$, which did not have a specialization in technology $\mathrm{z}$ at time $\mathrm{t}$, acquires that specialization at time $t+4$. Value 0

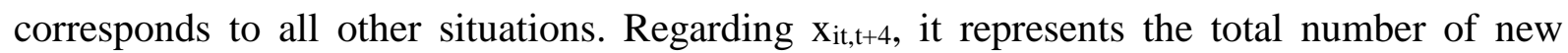
technological specializations in region $\mathrm{i}$ at $\mathrm{t}+4$.

However, one possible criticism underlying the use of such a variable is that it does not take into account differentiated regional diversification potentials: regions with more specializations are more limited in terms of diversification opportunities than are less diversified regions. To deal with this possible shortcoming, a diversification index is proposed, implemented as follows:

\footnotetext{
${ }^{6}$ As a robustness check, the empirical strategy proposed in section 5 was also implemented considering higher level of disaggregation (633 IPC subclasses), with results similar to those presented in section 6.
} 
Diversification $_{\mathrm{it}, \mathrm{t}+4}=\frac{x i t+4}{\mathrm{Xit}}$

where Diversification $_{i, t+4}$ represents how successful region $i$ is in terms of diversification between year $\mathrm{t}$ and $\mathrm{t}+4 ; \mathrm{X}_{\mathrm{it}}$ (diversification potential) is the total number of technologies in which, as of year $t$, region $i$ did not have a specialization; and $x_{i t+4}$ is defined as in (2). ${ }^{7}$ The index ranges between 0 and 1 , where 0 means that at $t+4$ region $i$ does not acquire any new specialization compared to year $\mathrm{t}$, and 1 indicates the opposite.

There are two possible limitations of the indicator proposed in (4). Firstly, the indicator might overestimate, by construction, the diversification of regions with more patents. To check this, the existing correlation is computed between the indicator for each region and period, and the number of patent applications in region $\mathrm{i}$ at time t. However, the correlation is very weak and not statistically significant (see table 1).

Second, the indicator proposed in (4) might be biased towards regions with lower diversification potential (denominator), overestimating their diversification. To investigate this, Table 1 shows the correlation between the numerator (number of new specializations at time $t+4$ ) and the denominator (diversification potential) of the proposed indicator in (4). The statistics reflect a moderately negative and statistically significant (at 0.01 level) correlation between both variables $(-0.47)$. This means that in the sample of observations there is some coincidence between the regions where more new specializations emerge at time $t+4$, and those with lower diversification potential. This is counter to the intention of constructing (4): the idea underlying the construction of (4) was to take into account the fact that regions with higher diversification potential would eventually create more new specializations than other regions. Therefore, in

\footnotetext{
${ }^{7}$ In most cases, the gain/loss of technologies by the regions is not the result of slight variations in the RCA. Such movements generally result from the introduction of completely new technologies/full abandonment of older ones (see Tables A1/A2 in Appendix A)
} 
(4), a ratio was proposed in order to avert penalizing regions with lower diversification potential. However, what actually happens is exactly the opposite.

To mitigate this problem, this article adapts the methodology proposed by Audretsch and Fritsch (2002) and followed by Xiao et al. (2018), and computes an adjusted diversification indicator. This indicator differs from (4) in that the diversification potential of each region $i$ and year $t$ is technology-adjusted. The number of specializations existing in each region is computed as if all of them had a similar (equal to the average) technological structure. Here the main objective is to attribute a higher/lower diversification potential to those regions whose technological structure is better developed in technologies where specializations are more/less likely to occur. The computation of the technology-adjusted diversification potential is described in Appendix B.

Table 1 shows the correlation between new specializations and the diversification potential (adjusted and non-adjusted). As it can be observed, the adjusted diversification potential mitigates, at least partially, the problem described above. The correlation between adjusted diversification potential and the number of new specializations is -0.26 , which is substantially lower than in the case of the diversification potential. As this alternative seems preferable, this study uses (4) computed using an adjusted diversification potential.

\section{$<$ Table $1>$}

\subsubsection{Cooperation}

This paper seeks to study cooperation between regional stakeholders relevant to S3 (i.e. regional actors that may intervene in any EDP, including, among others, firms, research institutions, higher education institutions). Therefore, it seems more appropriate to operationalize cooperation in terms of patent co-applications than in terms of patent co-inventions. Patents are invented by individuals that, usually, are affiliated to organizations, which in turn, are generally 
the assignees on a given patent (Morrison et al., 2017). As argued by Broekel et al. (2015), patents co-invention often concerns intra-organization collaboration, which, from the point of view of the organization, is not associated with any external source of knowledge. Conversely, the co-ownership of patents reflects collaborative projects that led to the joint development of these intellectual property rights. Therefore, following Chessa et al. (2013), to measure the intensity of regional cooperation between organizations, this paper examines whether patent applications in region i have more than one applicant. Taking the regional affiliation of the applicants into account, it distinguishes between cooperation within regions and cooperation between regions. To establish this distinction, intra-regional cooperation is seen as a process where there are only internal actors, while inter-regional collaboration is identified as a process including actors that are external to the region. Following this reasoning, cooperation within regions is measured by the following formula:

CooperationWithin $_{\text {it-t+4 }}=\frac{\sum_{t=1}^{5} \text { CPATWit }}{\sum_{t=1}^{5} \text { PATit }}$

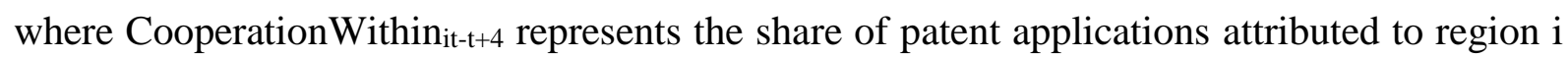
over the period $[t, t+4]$ that have more than one applicant, and all applicants belong to region $\mathrm{i}$. PAT $_{\text {it }}$ is then the total number of patent applications in region $\mathrm{i}$ in year $\mathrm{t}$, and $\mathrm{CPATW}_{\text {it }}$ is the total number of these patent applications that have more than one applicant, all of them from region $\mathrm{i}$.

Regarding cooperation between regions, it is evaluated as follows:

CooperationBetween $_{\text {it }-\mathrm{t}+4}=\frac{\sum_{t=1}^{5} \mathrm{CPATBit}}{\sum_{t=1}^{5} \text { PATit }}$

where CooperationBetween ${ }_{\text {it-t+4 }}$ represents the share of patent applications attributed to region i over the period $[t, t+4]$ that have more than one applicant, and where at least one applicant is not from region $\mathrm{i} . \mathrm{PAT}_{\mathrm{it}}$ is the total number of patent applications in region $\mathrm{i}$ in year $\mathrm{t}$, and 
$\mathrm{CPATB}_{i t}$ is the total number of these patent applications with more than one applicant, at least one of whom is not from region $i$. In both cases, cooperation ranges between 0 and $1 .{ }^{8}$

\subsection{Descriptive Statistics}

Table 2 presents descriptive statistics of the variables used in this analysis. The number of new specializations entering each region ranges between 1 and 31 . In the sample, 11 observations record the minimum, which is distributed across 7 regions located in 6 countries (Greece, Italy, Poland, Portugal, Romania and Slovakia). Lazio (ITI4) records the maximum in the period 2003-2007. On average, each region acquires 14 new specializations in each time period. The diversification index ranges between 0.0083 and 0.4444 . Sud-Est (RO22) in the period 20012005 records the minimum. The maximum is found for Lombardia (ITC4) in the period 20032007. The average value is equivalent to 0.15 and the standard deviation 0.06 .

Regarding cooperation, it is interesting to note that both types are completely absent from some regions in given periods. The maximum is higher for cooperation between regions $(0.83)$ than for cooperation within regions (0.5). The same applies to the average: on average, $14 \%$ of the patents to which a region holds a claim include co-applicants external to the region; this drops to $5 \%$ when only co-applicants from the region are accounted for. Table D1, in Appendix D, reports the correlation matrix. Although correlation is statistically significant for all pairs of variables, correlation coefficients are never very strong (except for the correlation between diversification and the number of new specializations). Therefore, multicollinearity is unlikely to affect the empirical strategy presented in the next section.

$<$ Table $2>$

\footnotetext{
${ }^{8}$ For the computation of these indexes, patent applications are counted as whole counting (see Maraut et al., 2008).
} 
Figure 1 shows that average diversification varies substantially across regions in Europe. Moreover, almost all regions with leading positions are located at the core of the European continent or in the north; lower scores predominate in eastern and southern Europe. Can the intensity of intra- and inter-regional cooperation explain such differences?

\section{$<$ Figure $1>$}

\section{Empirical strategy}

To answer the research questions, the following model is proposed:

$D_{i t, t+4}=\alpha+\beta_{1}$ CooperationWithin ${ }_{i t-t+4}+\beta_{2}$ CooperationBetween $_{i t-t+4}+\beta_{3} C_{i t}+\varepsilon_{i t}$

Two different model specifications are tested: in one, the dependent variable, D, takes the value of the natural logarithm of the total number of new specializations emerging in region i between $t$ and $\mathrm{t}+4$ (see eq. (2)); in the alternative specification, D corresponds to the logit transformation of Diversification $_{\mathrm{it}, \mathrm{t}+4}$, as defined in (4). As (4) is a fraction that never takes either 0 or 1 (see Table 2), the logit transformation is one possible solution to cope with the fact that a linear model with (4) as dependent variable would probably disregard the fractional nature of the index.

The explanatory variables in equation (7) are defined as above, and $\mathrm{C}_{\mathrm{it}}$ is a vector of control variables in region i and year t. As for $\alpha$, it represents a constant, while $\varepsilon_{\text {it }}$ represents the error term that accounts for all omitted variables. The objective is to estimate parameters $\beta$, to explain the impact of the explanatory variables on regional diversification. As this paper aims at exploring the panel characteristics of the dataset, it adopts a Fixed-Effects approach.

The introduction of $\mathrm{C}_{\mathrm{it}}$ as a vector of control variables is intended to mitigate, at least in part, potential endogeneity problems deriving from time-variant regional features that might simultaneously affect cooperation and diversification. The first aspect to consider is 
technological diversity, which, as discussed in section 3, may have a positive impact on diversification. Moreover, regional technological diversity may also influence the ability of regional organizations to develop intra- or inter-regional collaborative projects. EU support to the regions may also influence collaborative ties (for instance, if funding is conditional on the development of collaborative R\&D activities); at the same time, it may promote projects that foster or hamper diversification. This variable is particularly relevant because the time-span considered here includes two different programming periods: 2000-2006 and 2007-2013. Although the regional stock of human capital (percentage of population with tertiary education) is typically stable in the short run, it may change in the medium and long run. Changes in the quality of human capital that integrates regional organizations may affect their decisions concerning both the development of cooperative projects and the selection of the most promising technological domains to explore. It is also important to control for fluctuations in regional economic performance (unemployment rate) and total regional $\mathrm{R} \& \mathrm{D}$ expenditure, which may affect regional actors' behaviour regarding both the development of collaborative projects and propensity to diversify. Finally, the regional level of economic development (GDP per capita) is included because, as discussed in section 3, the role of cooperation may be differentiated for different levels of regional development. Most of these variables have been collected for each region at the beginning of each period (time $\mathrm{t}$ ). Appendix $\mathrm{C}$ describes the procedures adopted to compute all controls.

As diversification is measured for different overlapping periods, it may depend on past observations. Therefore, it is also important to test a model specification where one of the explanatory variables of (7) is the lagged dependent variable. To do so, this study proposes running a dynamic panel model, estimating the relevant coefficients using the General Method of Moments (GMM), in line with Arellano and Bond (1991) - an approach known as 
'Difference GMM' (Diff-GMM). ${ }^{9}$ It is implemented using the stata xtabond2 command, following Roodman (2009a). For Diff-GMM estimation, cooperation is considered as potentially endogenous, because it is measured throughout the same period of diversification (i.e. between $t$ and $t+4$ ). As both diversification and cooperation occur simultaneously, it may be the case that not only does cooperation influences diversification, but also the reverse. The remaining variables, most of them measured at the beginning of each five-year period (i.e. at time t), are considered exogenous. The exception is technological diversity, which is taken as a predetermined variable. Thus, this study assumes that diversity, as measured at time $t$, is not correlated with the error term at time $\mathrm{t}$ (as the error term accounts for unobserved factors that explain diversification between $\mathrm{t}$ and $\mathrm{t}+4$ ). However, it assumes that is reasonable to think there can be a correlation between diversity at time $t$, and the lagged values of the error term. The past outcome of diversification can have impacts on the current technological diversity existing in a given region. The use of Diff-GMM to estimate equation (7) addresses potential endogeneity problems, and also serves as a robustness check.

\section{Results}

Table 3 shows the Fixed-Effects and the Diff-GMM estimation results of equation (7), for both dependent variables discussed above. Specification (i) refers to the baseline model as proposed in (7). Fixed-Effects estimation results for specification (i) show that, regarding the main variables of interest, only cooperation between regions has a statistically significant impact (at 0.05 level) on regional diversification. The coefficient of cooperation within regions, when estimated by the GMM, is also statistically significant, but only at 0.1 level. In both cases coefficients are negative, regardless of the measure of diversification adopted. However, results regarding both forms of cooperation are not robust to both estimation methods. This means that

\footnotetext{
${ }^{9}$ System GMM failed to reject the non-existence of an autocorrelation of order 2.
} 
that each form of cooperation, per se, does not contribute to regional diversification. Conversely, as discussed in section 3, these results corroborate that the benefits of cooperation on knowledge creation are not always guaranteed (Broekel et al., 2015; De Noni et al., 2017), and that, under certain circumstances, cooperation (within or between regions) may even obstruct regional diversification, fostering lock-in (see Narula, 2000; Boschma, 2005). Thus, an important implication of this finding is that, for those regions whose S3 strategies foresee diversification into new technologies, strengthening their intra or inter-regional cooperation intensity is not enough. As explained below, cooperation processes must be carefully designed, to take into account the existing regional conditions.

\section{$<$ Table $3>$}

Specification (ii) interacts each one of the variables of interest with GDPpc (GDP per capita). To understand how the coefficients of these variables change for different levels of GDPpc, it is relevant to consult Table 4. Here, the strongest results concern cooperation within regions. The effect of cooperation within regions on diversification increases as regions become more developed. The effect is negative for very low levels of development, becoming positive as regional GDPpc increases. These results hold regardless of the dependent variable adopted and the estimation method used. However, with the GMM, results are weaker in terms of statistical significance. Regarding cooperation between regions, the results do not appear strong enough to permit inferences about the role of GDPpc as moderator.

\section{$<$ Table $4>$}

Specification (iii) is similar to specification (ii), only that in the (iii) is added the interaction between cooperation within regions and cooperation between regions. As shown in Table 3, the interaction effect is positive and statistically significant for both estimation methods and diversification measures. That indicates that inter-regional cooperation can help to boost the impact of cooperation within regions on diversification, and vice-versa. Table 5 shows the 
impact of cooperation within/between regions on regional diversification for various levels of GDPpc, as well as for various degrees of cooperation between/within regions. As to cooperation within regions, when GDPpc is very low, the impact on regional diversification may be negative or positive and not statistically significant. However, for higher levels of GDPpc, coefficients gradually become positive and statistically significant as cooperation between regions increases. Thus, in less developed and less diversified regions (i.e. regions with lower GDPpc) internal collaboration fosters diversification only when associated with high levels of external cooperation. Unless local actors actively integrate external collaboration networks, their internal cooperative efforts risk perpetuating existing technological paths. This means that in the context of S3, in less developed regions that aim at diversifying into new technologies, internal collaboration is an effective tool only if these regions collaborate intensively with partners outside of the region. As discussed in section 3, this provides a first hint of the existing complementarity between both forms of cooperation. Further, this complementarity is particularly relevant for less developed regions where, in the absence of knowledge flows from outside the region, processes of intra-regional collaboration may lead to a lock-in scenario.

For instance, taking into account specification (iii), an increase of 0.01 in the intensity intraregional cooperation may lead to changes in the number of new technological specializations ranging between $-4.28 \%$ and $+20.58 \%$. When diversification is measured using the indicator proposed in (4), due to the logit transformation, the interpretation is slightly different, although the general conclusions are similar. If the intensity of intra-regional cooperation increases by 0.01, this may lead to changes in the ratio between the degree of diversification and the degree of non-diversification of regions (hereafter 'ratio'), ranging between $-4.89 \%$ and $22.68 \% .^{10}$

\footnotetext{
${ }^{10}$ Improvement in the ratio necessarily implies an improvement in regional diversification.
} 
The sign and magnitude of such changes always depend on the intensity of inter-regional cooperation and the level of economic development of the regions.

Regarding cooperation between regions, when GDPpc is very low and cooperation within regions is not very high, the impact on regional diversification is, in most cases, not statistically significant. Otherwise, coefficients are always positive and statistically significant (Table 5). Further, coefficients become larger as cooperation within regions increases. This means that in less developed and diversified regions, internal actors are not able to explore the diversification opportunities deriving from external collaborations, unless these actors collaborate intensively among themselves. As discussed in section 3, this corroborates that intra and inter-regional collaboration complement each other. In the absence of internal collaboration, external collaboration is useless, because external knowledge does not circulate within the regional innovation system. The knowledge imported from outside of the region remains in a restricted number of organizations, who do not share it with other regional stakeholders, and are unable to transform it into new knowledge to the region. Thus, this is also an important lesson as regards S3 for European regions.

Table 5 also confirms that GDPpc has an incremental effect on the impact of both forms of cooperation on regional diversification. This supports the initial expectation that, in richer and more diversified environments, both forms of cooperation are more effective in fostering regional diversification. This has important implications regarding the potential role of cooperation and regional diversification. First, different regions may need to adopt differentiated strategies in terms of cooperation, depending on their level of economic development. Second, the complementarity between intra- and inter-regional collaboration is particularly relevant for less developed regions: without such complementarity, both forms of cooperation will be unable to foster regional diversification. Third, less developed regions need 
to take care in designing their strategies: the risk of failure in diversifying is higher than in more advanced regions.

\section{$<$ Table $5>$}

Overall, these results shed light on the relationship between regional collaboration and a regional feature not yet explored in this context: regional diversification. Previous empirical findings on the relationship between regional innovation and collaboration have showed that such a link seems to be described by an inverted-U curve: collaboration is more effective in fostering innovation when it is moderate, as well as when there is a balance between intra- and inter-regional collaboration (De Noni et al., 2017; Broekel, 2015; Broekel, 2012). Although the present work is not directly comparable to previous studies, the results discussed here confirm the existence of such a mutually beneficial relationship between both forms of cooperation. These findings also support qualitative studies that hold that more diverse and cooperative regional settings foster diversification, structural change and a successful S3 process (Grillitsch, 2016).

The estimated coefficients of the control variables do not appear strong enough to permit inferences: in the Diff-GMM, most of them are not statistically significant (see Table 3). An exception is diversity, where the coefficient is negative and strongly statistically significant in almost all model specifications. In view of Jacobian externalities, regional technological diversity might be expected to have a positive impact on regional diversification, but the econometric evidence contradicts this view. However, the impact of technological diversity on the inventive capacity of European regions is highly sensitive to the level of aggregation, so any policy conclusions here should be very cautious (Morescalchi \& Hardeman, 2015).

Finally, all model specifications control for time-fixed-effects. Although in Diff-GMM the Hansen test confirms the joint validity of the instruments (all suitable lags are used as instruments), the high number of instruments and the high p-value of the Hansen test in the 
third specification (very close to 1) may indicate a weak Hansen test with an implausible pvalue (Roodman, 2009b). Thus, Appendix E compares the Diff-GMM estimation results presented in Tables 3, 4 and 5 with those where only second-lag instruments are considered. Although the magnitude and statistical significance of some coefficients change, similar conclusions still hold when a far more limited number of instruments is adopted (see Appendix E).

\section{Conclusions}

This article has argued that the concept of S3 is strongly associated with the idea of diversification. It has investigated the drivers of technological diversification at the EU regional level, employing cooperation (distinguishing between cooperation within regions and cooperation between regions) as main explanatory variable.

Although cooperation within and between regions is important as a determinant of regional diversification, their role depends both on each other and on the level of regional development. In less developed regions, internal collaborative efforts may lead to technological lock-in, unless complemented by strong external collaboration networks able to break the vicious circle. Similarly, in the least developed regions, external collaboration does not serve to promote diversification, unless there is strong interaction among actors within the region, allowing external knowledge to flow within the system. Conversely, in the most developed regions, cooperation within/between regions contributes to regional diversification, regardless of the degree of external/internal collaboration. However, even in these cases, each form of cooperation strengths the positive effect of the other as regards achieving regional diversification. Thus, regional innovation systems should be well integrated, internally and externally - otherwise, cooperation may prove ineffective for boosting regional diversification. 
These results are relevant for a better understanding of S3 in European regions. Generally, cooperation within and between regions may have a positive impact on any S3 process, but joint implementation is essential. Although the literature has focused on involving various regional actors in identifying new regional priority areas, the results presented here indicate that the collaborative involvement of external actors can promote the effectiveness of this process of entrepreneurial discovery. Any policy designed to promote regional-level research collaboration should involve careful assessment of each region as to performance regarding both forms of cooperation. Such assessment can indicate whether policies should focus on cooperation within regions, between regions, or both.

As discussed by De Noni et al. (2017), European regions differ in their preferences regarding collaboration: while some Scandinavian and Latin regions show a strong preference for internal collaboration, inter-regional collaboration is preferred by some regions in Benelux, Germany and Central and Eastern Europe. Therefore, for different groups of regions differentiated policies may be required. In terms of $\mathrm{S} 3$, and in order to include external actors in the entrepreneurial discovery process, this may prove easier in regions with a clear preference for external collaboration. In these cases, strong external networks already exist, ready to be activated. Here the challenge is probably to reinforce internal collaboration networks between regional actors. Conversely, in regions with a preference for internal collaboration, the main challenge is to reinforce external networks. This may help to integrate external partners in the entrepreneurial discovery process of these regions.

The focus here has been on the relationship between the intensity of inter-organizational collaboration (as measured by co-applications for patents) and technological diversification, and its implications for S3. However, such an approach is not without its limitations. On the one hand, collaboration between organizations can be measured through other forms, beyond patent co-applications. Fritsch et al. (2018) describe, for the case of Germany, regional 
knowledge networks combining various sorts of data (co-patents, co-publications, as well as collaborative R\&D projects subsidized by public funding). These authors find the use of single data sources may underestimate existing regional knowledge interactions. Thus, a possible limitation of this paper may be that it focuses on a single form of collaboration, that based on patent data. One avenue for future research could be to extend such comprehensive combined measures of collaboration to other European regions in other countries. On the other hand, S3 has many other dimensions beyond the technological. However, this work has relied on patent data, disregarding other regional aspects also relevant for S3, like industries, human capital, research, and education and training. Although these findings are useful for better understanding S3, a more comprehensive framework will be required to shed light on the determinants of regional diversification in terms of other regional capabilities.

\section{References}

Arellano, M. \& Bond, S. (1991). Some tests of specification for panel data: Monte Carlo evidence and an application to employment equations, Review of Economic Studies, 58, 277297.

Asheim, B., Grillitsch, M. \& Trippl, M. (2016). Smart specialization as an innovation-driven strategy for economic diversification: Examples from Scandinavian regions, Papers in Innovation Studies, 2016/23

Audretsch, D. B. \& Fritsch, M. (2002). Growth regimes over time and space, Regional Studies, 36 (2), 113-124

Balland, P.A., Boschma, R., Crespo, J. \& Rigby, D. (2018). Smart specialization policy in the EU: Relatedness, knowledge complexity and regional diversification, Regional Studies, DOI: $10.1080 / 00343404.2018 .1437900$ 
Bathelt, H., Malmberg, A. \& Maskell, P. (2004). Clusters and knowledge: local buzz, global pipelines and the process of knowledge creation, Progress in Human Geography, 28, 31-56

Boschma, R. (2005). Proximity and innovation: A critical assessment, Regional Studies, 39, $61-74$

Boschma, R., Balland, P.A. \& Kogler, D.F., (2015). Relatedness and technological change in cities: the rise and fall of technological knowledge in US metropolitan areas from 1981 to 2010, Industrial and Corporate Change, 24, 223-250.

Boschma, R. \& Giannelle, C. (2014). Regional branching and smart specialization policy, S3 Policy Brief Series 06/2014

Boschma, R. \& Iammarino, S. (2009). Related variety, trade linkages, and regional growth in Italy, Economic Geography, 85(3), 289-311

Boschma, R., Minondo, A. \& Navarro, M. (2013). The emergence of new industries at the regional level in Spain: A proximity approach based on product relatedness, Economic Geography, 89, 29-51.

Boschma, R. \& ter Wal, A. (2007). Knowledge networks and innovative performance in an industrial district: The case of a footwear district in the South of Italy, Industry and Innovation, $14(2), 177-199$

Broekel, T. (2012). Collaboration intensity and regional innovation efficiency in Germany: A conditional efficiency approach, Industry and Innovation, 19(3), 155-179.

Broekel, T. \& Boschma, R. (2012). Knowledge networks in the Dutch aviation industry: the proximity paradox, Journal of Economic Geography, 12, 409-433 
Broekel, T., Buerger, M. \& Brenner, T. (2015). An investigation of the relation between cooperation and the innovative success of German regions, Spatial Economic Analysis, 10(1), $52-78$.

Capello, R. \& Kroll, H. (2016). From theory to practice in smart specialization strategy: emerging limits and possible future trajectories, European Planning Studies, 24, 1393-1406

Chessa, A., Morescalchi, A., Pammolli, F., Penner, O., Petersen, A. M., \& Riccaboni, M. (2013). Is Europe evolving toward an integrated research area?, Science, 339, 650.

Cortinovis, N., Xiao, J., Boschma, R. \& van Oort, F. (2017). Quality of government and social capital as drivers of regional diversification in Europe, Journal of Economic Geography, http://doi.org/10.1093/jeg/lbx001

De Noni, I., Ganzaroli, A. \& Orsi, L. (2017). The impact of intra- and inter-regional knowledge collaboration and technological variety on the knowledge productivity of European regions, Technological Forecasting \& Social Change, http://dx.doi.org/10.1016/j.techfore.2017.01.003

Essletzbichler, J. (2015). Relatedness, industrial branching and technological cohesion in US metropolitan areas, 1975-1997, Regional Studies, 49, 752-766.

Faems, D., Looy, B. V. \& Debackere, K. (2005). Interorganizational collaboration and innovation: toward a portfolio approach, Journal of Product Innovation Management, 22, 238250.

Fagerberg, J. \& Shrolec, M. (2016). Explaining regional economic performance: the role of competitiveness, specialization and capabilities, Papers in Innovation Studies 2016/2

Fitjar, R.D. \& Rodríguez-Pose, A. (2013). Firm collaboration and modes of innovation in Norway, Research Policy, 42, 128-138.

Foray, D. (2013). The economic fundamentals of smart specialisation, Ekonomiaz, 83, 83-102. 
Foray, D., David, P.A. \& Hall, B.H. (2009). Smart specialization: the concept, Knowledge Economists Policy Brief, 9, Brussels: European Commission.

Foray, D., David, P. \& Hall, B. (2011). Smart specialization: From academic idea to political instrument, the surprising career of a concept and the difficulties involved in its implementation, MTEI Working Paper. Lausanne: Management of Technology and Entrepreneurship Institute.

Foray, D., Goddard, J., Beldarrain, X., Landabaso, M., McCann, P., Morgan, K., Nauwelaers, C. \& Ortega-Argiles, R. (2012). Guide to research and innovation strategies for smart specialization (RIS 3), European Union Regional Policy, March.

Fritsch, M. (2003). Does R\&D-Cooperation Behavior Differ Between Regions?, Industry and Innovation, 10(1), 25-39.

Fritsch, M. (2004). Cooperation and the efficiency of regional R\&D activities, Cambridge Journal of Economics, 28, 829-846.

Fritsch, M., Titze, M. \& Piontek, M. (2018). Knowledge interactions in regional innovation networks: Comparing data sources, Jena Economic Research Papers, 2018-003, FriedrichSchiller-University Jena.

Graf, H. (2011). Gatekeepers in regional networks of innovation, Cambridge Journal of Economics, 35, 173-198

Grillitsch, M. (2016). Institutions, smart specialisation dynamics and policy, Environment and Planning C: Government and Policy, 34, 22-37

Maraut, S., Dernis, H., Webb, V., Spiezia, V. \& Guellec, D. (2008). The OECD REGPAT database: A presentation, OECD STI Working Papers, 2008/02. 
McCann, P. \& Ortega-Argilés. R. (2011). Smart specialization, regional growth and applications to European Union Cohesion Policy, Economic Geography Working Paper 2011, Faculty of Spatial Sciences, University of Groningen

McCann, P. \& Ortega-Argilés. R. (2015). Smart specialization, regional growth and applications to European Union Cohesion Policy, Regional Studies, 49, 1291-1302

Morescalchi, A. \& Hardeman, S. (2015). Diversity and the technological impact of inventive activity: evidence for EU regions, JRC Technical Report, Report EUR 27375

Morgan, K. (2013). The regional state in the era of smart specialization, Ekonomiaz 83, 102125.

Morgan, K. (2016). Collective entrepreneurship: the Basque model of innovation, European Planning Studies, 24 1544-1560.

Morrison, G., Riccaboni, M. \& Pammolli, M. (2017). Data descriptor: Disambiguation of patent inventors and assignees using high-resolution geolocation data, Scientific Data, 4:170064, DOI: 10.1038/sdata.2017.64

Narula, R. (2002). Innovation systems and inertia in R\&D location: Norwegian firms and the role of systemic lock-in, Research Policy 31, 795-816

Neffke, F., Henning, M. \& Boschma, R. (2011). How do regions diversify over time? Industry relatedness and the development of new growth paths in regions, Economic Geography, 87, $237-265$

Nooteboom, B. (2000). Learning by interaction: absorptive capacity, cognitive distance and governance, Journal of Management and Governance, 4, 69-92

OECD, REGPAT database, February 2016 
OECD (2009). Patents as statistical indicators of science and technology. Paris: OECD

Petralia, S., Balland, P.A., \& Morrison, A. (2017). Climbing the ladder of technological development, Research Policy, 46, 956-969.

Rigby, D. (2015). Technological relatedness and knowledge space: Entry and exit of US cities from patent classes, Regional Studies, 49, 1922-1937

Rodríguez-Pose, A. \& Crescenzi, R. (2008). Mountains in a flat world: why proximity still matters for the location of economic activity, Cambridge Journal of Regions, Economy and Society, 1 (3), 371-388

Roodman, D. (2009a). How to do xtabond2: An introduction to difference and system GMM in Stata, The Stata Journal, 9, 86-136

Roodman, D. (2009b). PRACTITIONERS' CORNER - A Note on the Theme of Too Many Instruments, Oxford Bulletin of Economics and Statistics, 71, 1

Sun, Y. (2016). The structure and dynamics of intra- and inter-regional research collaborative networks: the case of China (1985-2008). Technological Forecasting \& Social Change, 108, 70-82.

Sun, Y., \& Cao, C. (2015). Intra- and inter-regional research collaboration across organizational boundaries: evolving patterns in China, Technological Forecasting and Social Change, 96, $215-231$

Uyarra, E., Sörvik, J. \& Midtkandal, I. (2014). Inter-regional collaboration in research and innovation strategies for smart specialisation (RIS3), S3 Working Paper Series, 06/2014

Xiao, J., Boschma, R. \& Andersson, M. (2018). Industrial diversification in Europe: The differentiated role of relatedness, Economic Geography, DOI: $10.1080 / 00130095.2018 .1444989$ 
Table 1. Correlation Matrix: Diversification / Adjusted Diversification and other potentially relevant variables for construction of these indicators

\begin{tabular}{|c|c|c|c|c|c|c|}
\hline & 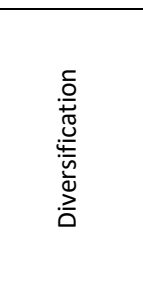 & 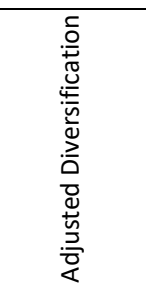 & 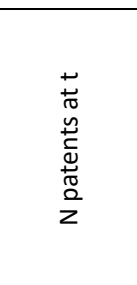 & 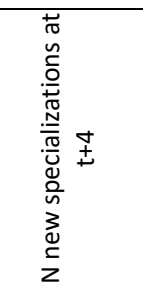 & 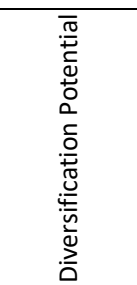 & 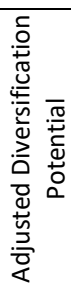 \\
\hline Diversification & 1 & & & & & \\
\hline Adjusted Diversification & $0.935^{* * *}$ & 1 & & & & \\
\hline $\mathrm{N}$ patents at $\mathrm{t}$ & 0.010 & $0.184 * * *$ & 1 & & & \\
\hline $\begin{array}{l}N \text { new specializations at } \\
\qquad+4\end{array}$ & $0.952^{* * *}$ & $0.914^{* * *}$ & $-0.061 * * *$ & 1 & & \\
\hline Diversification Potential & $-0.682 * * *$ & $-0.611 * * *$ & $-0.249 * * *$ & $-0.466 * * *$ & 1 & \\
\hline $\begin{array}{l}\text { Adjusted Diversification } \\
\text { Potential }\end{array}$ & $-0.405^{* * *}$ & $-0.591 * * *$ & $-0.596 * * *$ & $-0.262^{* * *}$ & $-0.692 * * *$ & 1 \\
\hline
\end{tabular}

$* p<0.1, * * p<0.05, * * * p<0.01$ 
Table 2. Descriptive Statistics

\begin{tabular}{l|ccccc}
\hline \multicolumn{1}{c|}{ Variables } & $\mathrm{N}$ & mean & $\max$ & $\min$ & std dev \\
\hline N new specializations & 2260 & 13.84 & 31 & 1 & 5.30 \\
Diversification & 2260 & 0.15 & 0.44 & 0.01 & 0.06 \\
CooperationWithin & 2260 & 0.05 & 0.50 & 0.00 & 0.05 \\
CooperationBetween & 2260 & 0.14 & 0.83 & 0.00 & 0.10 \\
Diversity & 2260 & 0.10 & 0.35 & 0.00 & 0.06 \\
EU regional support & 2260 & 0.00 & 0.05 & 0.00 & 0.01 \\
Un_rate & 2260 & 8.00 & 27.30 & 1.20 & 4.61 \\
Tertiary_edu & 2260 & 22.56 & 50.80 & 3.70 & 8.01 \\
GDPpc & 2260 & 23.20 & 83.11 & 4.10 & 8.60 \\
R\&D & 2260 & 1.46 & 12.19 & 0 & 1.15 \\
\hline SOurce: authors & & & & &
\end{tabular}

Source: author's computations 
Figure 1. Average diversification of European Regions over the 10 periods analysed.

1-Berlin; 2-Madrid; 3-Paris; 4-Rome; 5-London

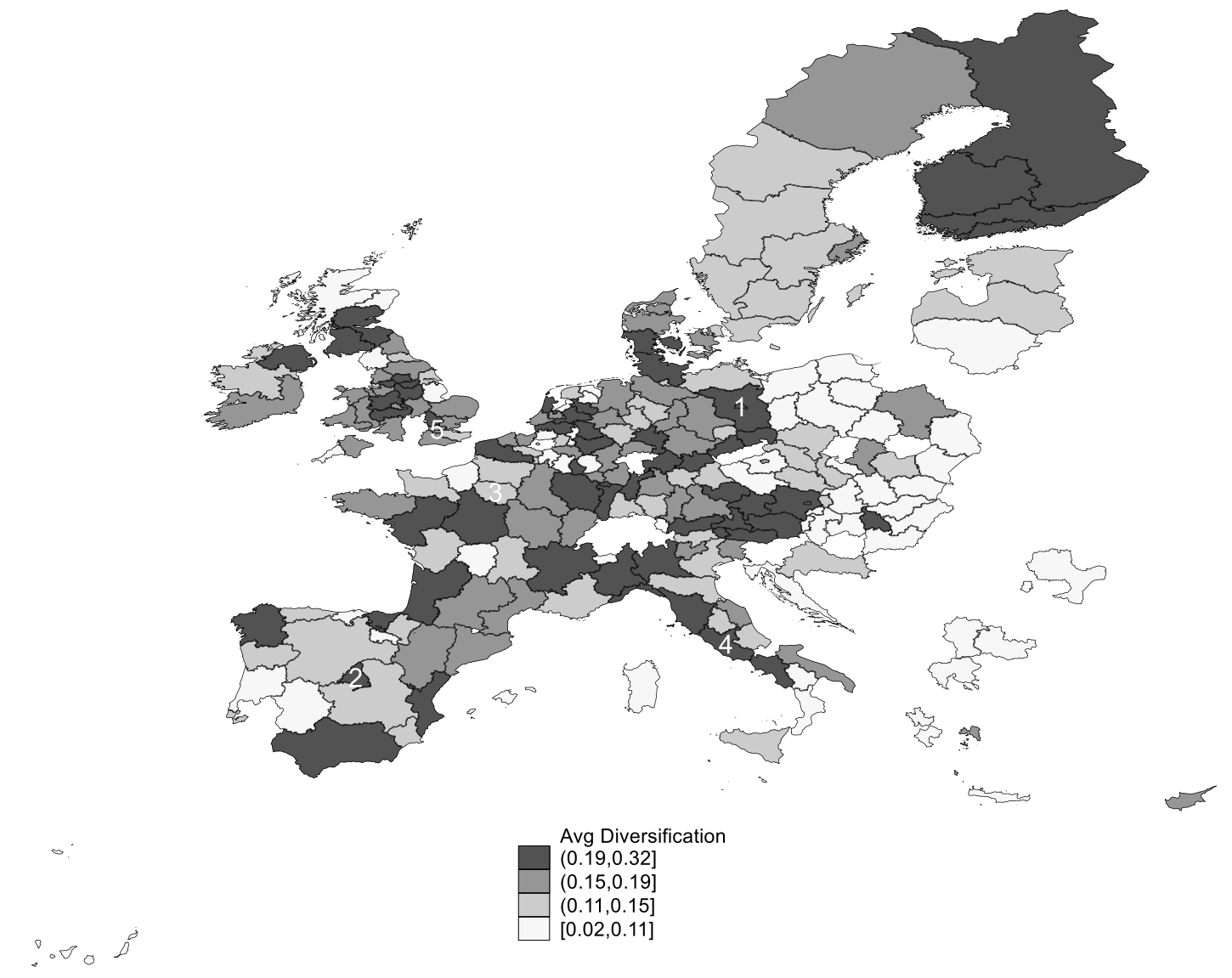

Source: author's computations 
Table 3. Estimation results - Fixed Effects and Difference GMM

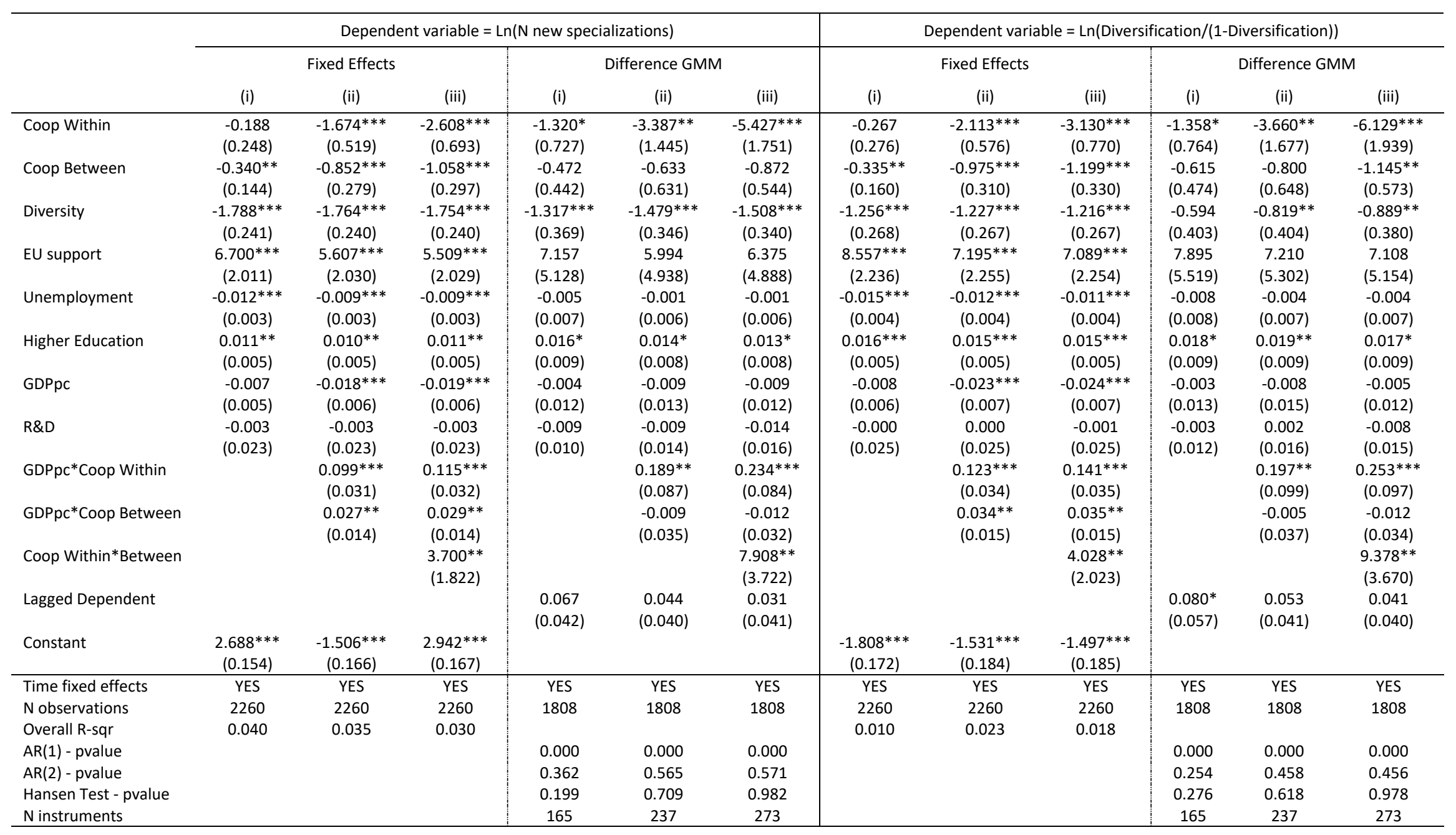

${ }^{*} p<0.1, * * p<0.05, * * * p<0.01$

Source: author's computations 
Table 4. Marginal effects of cooperation within regions and between regions, on the dependent variable, for differing levels of GDPpc

\begin{tabular}{|c|c|c|c|c|c|c|c|c|c|}
\hline \multirow{3}{*}{ Independent Variable } & \multicolumn{4}{|c|}{ Ln(N new specializations) } & \multicolumn{4}{|c|}{$\begin{array}{c}\operatorname{Ln}(\text { Diversification/(1- } \\
\text { Diversification)) }\end{array}$} & \multirow{3}{*}{$\begin{array}{l}\text { Assumption for the } \\
\text { interaction term } \\
\text { GDP pc }=\min \end{array}$} \\
\hline & \multicolumn{2}{|c|}{$\mathrm{FE}$} & \multicolumn{2}{|c|}{$\begin{array}{l}\text { Difference } \\
\text { GMM }\end{array}$} & \multicolumn{2}{|c|}{$\mathrm{FE}$} & \multicolumn{2}{|c|}{$\begin{array}{l}\text { Difference } \\
\text { GMM }\end{array}$} & \\
\hline & -1.27 & $* * *$ & -2.46 & $* *$ & -1.61 & $* * *$ & -2.70 & $* *$ & \\
\hline & 0.14 & & 0.24 & & 0.14 & & 0.12 & & $\mathrm{GDP} p \mathrm{c}=\mathrm{Q} 1$ \\
\hline \multirow[t]{5}{*}{ Cooperation within } & 0.58 & $*$ & 1.03 & & 0.69 & $*$ & 0.95 & & $\mathrm{GDP} p \mathrm{p}=\mathrm{Q} 2$ \\
\hline & 1.00 & $* *$ & 1.84 & & 1.21 & $* *$ & 1.79 & & $\mathrm{GDP} p \mathrm{p}=\mathrm{Q} 3$ \\
\hline & 6.55 & $* * *$ & 12.30 & $* *$ & 8.11 & $* * *$ & 12.71 & $*$ & $\mathrm{GDP} p \mathrm{c}=\max$ \\
\hline & -0.74 & $* * *$ & -0.68 & & -0.84 & $* * *$ & -0.82 & & GDP $p c=\min$ \\
\hline & -0.36 & $* *$ & -0.81 & $* *$ & -0.36 & $* *$ & -0.89 & $* *$ & $\mathrm{GDP} p \mathrm{c}=\mathrm{Q} 1$ \\
\hline \multirow[t]{3}{*}{ Cooperation between } & -0.24 & & -0.84 & $*$ & -0.21 & & -0.91 & $*$ & $\mathrm{GDP} p \mathrm{c}=\mathrm{Q} 2$ \\
\hline & -0.13 & & -0.88 & & -0.07 & & -0.93 & & $\mathrm{GDP} p \mathrm{c}=\mathrm{Q} 3$ \\
\hline & 1.38 & & -1.38 & & 1.82 & $*$ & -1.20 & & $\mathrm{GDP} p \mathrm{c}=\max$ \\
\hline
\end{tabular}

$* p<0.1, * * p<0.05, * * * p<0.01$

Source: author's computations 
Table 5. Marginal effects of cooperation within regions and between regions, on the dependent variable, for differing levels of interaction terms

\begin{tabular}{|c|c|c|c|c|c|c|c|c|c|c|}
\hline \multirow[b]{2}{*}{$\begin{array}{l}\text { Independent } \\
\text { Variable }\end{array}$} & \multicolumn{4}{|c|}{ Ln(N new specializations) } & \multicolumn{4}{|c|}{$\begin{array}{l}\operatorname{Ln}(\text { Diversification/(1- } \\
\text { Diversification)) }\end{array}$} & \multirow{2}{*}{\multicolumn{2}{|c|}{$\begin{array}{l}\text { Assumption for the } \\
\text { interaction terms }\end{array}$}} \\
\hline & \multicolumn{2}{|c|}{ FE } & \multicolumn{2}{|c|}{$\begin{array}{l}\text { Difference } \\
\text { GMM }\end{array}$} & \multicolumn{2}{|c|}{$\mathrm{FE}$} & \multicolumn{2}{|c|}{$\begin{array}{l}\text { Difference } \\
\text { GMM }\end{array}$} & & \\
\hline \multirow{5}{*}{$\begin{array}{l}\text { Cooperation } \\
\text { within }\end{array}$} & -2.13 & $* * *$ & -4.28 & $* * *$ & -2.55 & $* * *$ & -4.89 & $* * *$ & $\mathrm{GDP} p \mathrm{c}=\min$ & \multirow{5}{*}{$\begin{array}{c}\text { Cooperation } \\
\text { between }= \\
\text { min }\end{array}$} \\
\hline & -0.50 & & -0.93 & & -0.55 & & -1.27 & & $\mathrm{GDP} p \mathrm{c}=\mathrm{Q} 1$ & \\
\hline & 0.02 & & 0.05 & & 0.08 & & -0.20 & & $\mathrm{GDP} p \mathrm{c}=\mathrm{Q} 2$ & \\
\hline & 0.51 & & 1.06 & & 0.67 & & 0.88 & & $\mathrm{GDP} p \mathrm{c}=\mathrm{Q} 3$ & \\
\hline & 6.98 & $* * *$ & 14.03 & $* *$ & 8.57 & $* * *$ & 14.92 & $* *$ & GDP $p c=\max$ & \\
\hline \multirow{5}{*}{$\begin{array}{l}\text { Cooperation } \\
\text { within }\end{array}$} & -1.70 & $* * *$ & -3.32 & $* * *$ & -2.08 & $* * *$ & -3.74 & $* * *$ & $\mathrm{GDP} p \mathrm{c}=\min$ & \multirow{5}{*}{$\begin{array}{c}\text { Cooperation } \\
\text { between = } \\
\text { Q2 }\end{array}$} \\
\hline & -0.06 & & 0.03 & & -0.08 & & -0.12 & & $\mathrm{GDP} p \mathrm{c}=\mathrm{Q1}$ & \\
\hline & 0.46 & & 1.02 & & 0.56 & & 0.94 & & $\mathrm{GDP} p \mathrm{c}=\mathrm{Q} 2$ & \\
\hline & 0.94 & $* *$ & 2.02 & $*$ & 1.15 & $* *$ & 2.03 & & $\mathrm{GDP} p \mathrm{c}=\mathrm{Q3}$ & \\
\hline & 7.42 & $* * *$ & 15.00 & $* * *$ & 9.05 & $* * *$ & 16.06 & $* *$ & $\mathrm{GDP} p \mathrm{c}=\max$ & \\
\hline \multirow{5}{*}{$\begin{array}{l}\text { Cooperation } \\
\text { within }\end{array}$} & 0.93 & & 2.26 & & 0.78 & & 2.87 & * & $\mathrm{GDP} p \mathrm{c}=\min$ & \multirow{5}{*}{$\begin{array}{c}\text { Cooperation } \\
\text { between }= \\
\max \end{array}$} \\
\hline & 2.56 & $* *$ & 5.61 & $* *$ & 2.78 & $* *$ & 6.49 & $* *$ & $\mathrm{GDP} p \mathrm{c}=\mathrm{Q1}$ & \\
\hline & 3.08 & $* *$ & 6.60 & $* *$ & 3.41 & $* *$ & 7.56 & $* * *$ & $\mathrm{GDP} p \mathrm{c}=\mathrm{Q} 2$ & \\
\hline & 3.57 & $* * *$ & 7.60 & $* * *$ & 4.00 & $* * *$ & 8.65 & $* * *$ & GDP $p c=Q 3$ & \\
\hline & 10.04 & $* * *$ & 20.58 & $* * *$ & 11.90 & $* * *$ & 22.68 & $* * *$ & $\mathrm{GDP} p \mathrm{c}=\max$ & \\
\hline \multirow{5}{*}{$\begin{array}{l}\text { Cooperation } \\
\text { between }\end{array}$} & -0.59 & $*$ & 0.27 & & -0.62 & $*$ & 0.10 & & $\mathrm{GDP} p \mathrm{c}=\min$ & \multirow{5}{*}{$\begin{array}{c}\text { Cooperation } \\
\text { within }= \\
\min \end{array}$} \\
\hline & 1.05 & $*$ & 3.62 & $* *$ & 1.38 & $* *$ & 3.72 & $*$ & $\mathrm{GDP} p \mathrm{c}=\mathrm{Q1}$ & \\
\hline & 1.57 & $* *$ & 4.61 & $* *$ & 2.01 & $* *$ & 4.78 & $* *$ & $\mathrm{GDP} p \mathrm{c}=\mathrm{Q} 2$ & \\
\hline & 2.06 & $* *$ & 5.61 & $* *$ & 2.60 & $* * *$ & 5.87 & $* *$ & $\mathrm{GDP} p \mathrm{c}=\mathrm{Q} 3$ & \\
\hline & 8.53 & $* * *$ & 18.59 & $* * *$ & 10.50 & $* * *$ & 19.90 & $* *$ & GDP $p c=\max$ & \\
\hline \multirow{5}{*}{$\begin{array}{l}\text { Cooperation } \\
\text { between }\end{array}$} & -0.47 & & 0.53 & & -0.49 & & 0.40 & & $\mathrm{GDP} p \mathrm{c}=\min$ & \multirow{5}{*}{$\begin{array}{l}\text { Cooperation } \\
\text { within = Q2 }\end{array}$} \\
\hline & 1.17 & $*$ & 3.88 & $* *$ & 1.51 & $* *$ & 4.02 & $* *$ & GDP $p c=Q 1$ & \\
\hline & 1.69 & $* *$ & 4.86 & $* *$ & 2.14 & $* *$ & 5.08 & $* *$ & $\mathrm{GDP} p \mathrm{c}=\mathrm{Q} 2$ & \\
\hline & 2.18 & $* *$ & 5.87 & $* *$ & 2.73 & $* * *$ & 6.17 & $* *$ & $\mathrm{GDP} p \mathrm{c}=\mathrm{Q} 3$ & \\
\hline & 8.65 & $* * *$ & 18.84 & $* * *$ & 10.63 & $* * *$ & 20.20 & $* *$ & $\mathrm{GDP} p c=\max$ & \\
\hline \multirow{5}{*}{$\begin{array}{l}\text { Cooperation } \\
\text { between }\end{array}$} & 1.26 & & 4.23 & $* *$ & 1.39 & & 4.79 & $* *$ & $\mathrm{GDP} p \mathrm{c}=\min$ & \multirow{5}{*}{$\begin{array}{c}\text { Cooperation } \\
\text { within }= \\
\max \end{array}$} \\
\hline & 2.90 & $* *$ & 7.58 & $* * *$ & 3.39 & $* * *$ & 8.41 & $* * *$ & $\mathrm{GDP} p \mathrm{c}=\mathrm{Q} 1$ & \\
\hline & 3.42 & $* * *$ & 8.56 & $* * *$ & 4.02 & $* * *$ & 9.47 & $* * *$ & $\mathrm{GDP} p \mathrm{c}=\mathrm{Q} 2$ & \\
\hline & 3.91 & $* * *$ & 9.57 & $* * *$ & 4.62 & $* * *$ & 10.56 & $* * *$ & $\mathrm{GDP} p \mathrm{c}=\mathrm{Q3}$ & \\
\hline & 10.38 & $* * *$ & 22.54 & $* * *$ & 12.52 & $* * *$ & 24.59 & $* * *$ & $\mathrm{GDP} p c=\max$ & \\
\hline
\end{tabular}

${ }^{*} p<0.1,{ }^{* *} p<0.05,{ }^{* * *} p<0.01$

Source: author's computations 


\section{Appendix A: Statistics on specializations gained and lost by the regions}

Table A1. Number of new technological specializations at time $t+4$ (in comparison to time to time $t$ ), by period and RCA of the technology at time $t$

\begin{tabular}{c|cccccc}
\hline Periods & RCA $=0$ & $0<$ RCA $\leq 0.25$ & $0.25<$ RCA $\leq 0.5$ & $0.5<$ RCA $\leq 0.75$ & $0.75<\mathrm{RCA} \leq 1$ & $\mathrm{RCA} \geq 0$ \\
\hline $2000-2004$ & 2171 & 102 & 226 & 268 & 312 & 3079 \\
$2001-2005$ & 2222 & 92 & 247 & 267 & 274 & 3102 \\
$2002-2006$ & 2173 & 102 & 243 & 303 & 322 & 3143 \\
$2003-2007$ & 2247 & 111 & 242 & 312 & 308 & 3220 \\
$2004-2008$ & 2141 & 122 & 243 & 279 & 312 & 3097 \\
$2005-2009$ & 2227 & 102 & 243 & 283 & 300 & 3155 \\
$2006-2010$ & 2145 & 104 & 250 & 310 & 310 & 3119 \\
$2007-2011$ & 2099 & 104 & 258 & 329 & 318 & 3108 \\
$2008-2012$ & 2144 & 85 & 267 & 304 & 336 & 3136 \\
$2009-2013$ & 2113 & 109 & 260 & 290 & 353 & 3125 \\
Total & 21682 & 1033 & 2479 & 2945 & 3145 & 31284 \\
\hline
\end{tabular}

Source: author's computations

Table A2. Number of technological specializations at time $t$, in which the region is not specialized in at $\mathrm{t}+4$, by period and RCA of the technology at time $\mathrm{t}+4$

\begin{tabular}{c|cccccc}
\hline Periods & RCA $=0$ & $0<$ RCA $\leq 0.25$ & $0.25<$ RCA $\leq 0.5$ & $0.5<$ RCA $\leq 0.75$ & $0.75<R C A \leq 1$ & $R C A \geq 0$ \\
\hline $2000-2004$ & 1959 & 105 & 252 & 291 & 350 & 2957 \\
$2001-2005$ & 1983 & 106 & 223 & 282 & 310 & 2904 \\
$2002-2006$ & 1975 & 104 & 258 & 333 & 308 & 2978 \\
$2003-2007$ & 1998 & 111 & 257 & 377 & 337 & 3080 \\
$2004-2008$ & 2013 & 95 & 258 & 296 & 356 & 3018 \\
$2005-2009$ & 1997 & 108 & 283 & 344 & 372 & 3104 \\
$2006-2010$ & 2022 & 103 & 271 & 349 & 364 & 3109 \\
$2007-2011$ & 2075 & 119 & 266 & 345 & 344 & 3149 \\
$2008-2012$ & 2077 & 102 & 245 & 318 & 336 & 3078 \\
$2009-2013$ & 2091 & 117 & 263 & 336 & 347 & 3154 \\
Total & 20190 & 1070 & 2576 & 3271 & 3424 & 30531 \\
\hline
\end{tabular}

Source: author's computations 


\section{Appendix B: Computation of the technology-adjusted diversification potential}

$\underline{\text { Step 1: Computation of expected number of patents for each region } \mathrm{i} \text {, technology } \mathrm{z} \text { and year } \mathrm{t}}$

$\mathrm{E}\left(\mathrm{N}_{\mathrm{izt}}\right)=\mathrm{N}_{\mathrm{it}} \mathrm{S}_{\mathrm{zt}}$

such that:

$\mathrm{N}_{\mathrm{it}}=\sum_{z=1}^{n} N i z t$

$\mathrm{S}_{\mathrm{Zt}}=\frac{N z t}{N t}=\frac{\sum_{i=1}^{m} N i z t}{\sum_{i=1}^{m} \sum_{z=1}^{n} N i z t}$

where $\mathrm{N}$ represents the number of patents, subscripts $\mathrm{i}, \mathrm{z}$ and $\mathrm{t}$ concern region $\mathrm{i}$, technology $\mathrm{z}$ and year $\mathrm{t}$, and $\mathrm{m}$ and $\mathrm{n}$ are the total number of regions and technologies existing in my sample. $\mathrm{E}\left(\mathrm{N}_{\mathrm{izt}}\right)$ is the expected number of patents for each region i, technology $\mathrm{z}$ and year $\mathrm{t}, \mathrm{N}_{\mathrm{it}}$ represents the total number of patents in region $\mathrm{i}$ at time $\mathrm{t}$, and $\mathrm{S}_{\mathrm{zt}}$ refers to the world (all regions) share of patents for technology $\mathrm{z}$ at time $\mathrm{t}$.

$\underline{\text { Step 2: Computation of expected number of specializations for each region } \mathrm{i} \text { in year } \mathrm{t}}$

$\mathrm{E}\left(\operatorname{Spec}_{\mathrm{it}}\right)=\sum_{z=1}^{n}[\mathrm{E}(\mathrm{Nizt}) \mathrm{E}(\text { SpecRate } \mathrm{zt})]^{\prime}$

such that:

$\mathrm{E}\left(\right.$ SpecRate $\left._{\mathrm{zt}}\right)=\frac{\text { NewSpeczt }}{N z t}=\frac{\sum_{i=1}^{m} \text { NewSpecizt }}{\sum_{i=1}^{m} \text { Nizt }}$

$[\mathrm{E}(\text { Nizt }) \mathrm{E}(\text { SpecRate } \mathrm{zt})]^{\prime}=1$ if $\mathrm{E}(\mathrm{Nizt}) \mathrm{E}($ SpecRate $\mathrm{zt}) \geq 1$

$[\mathrm{E}(\mathrm{Nizt}) \mathrm{E}(\text { SpecRate } \mathrm{zt})]^{\prime}=0$ if $\mathrm{E}(\mathrm{Nizt}) \mathrm{E}($ SpecRate $\mathrm{zt})<1$

where $\mathrm{E}\left(\mathrm{Spec}_{\mathrm{it}}\right)$ is the expected number of specializations in region $\mathrm{i}$ and year $\mathrm{t} . \mathrm{E}\left(\mathrm{SpecRate} \mathrm{zt}_{\mathrm{t}}\right)$ is the ratio between the number of specializations in technology $\mathrm{z}$ at time $\mathrm{t}$, considering all 
regions included in the sample, and the number of patents in technology $\mathrm{z}$ at time $\mathrm{t}$, again taking into account all regions included in the sample of observations. Condition (6A) is added to take into account the fact that the specialization status of a given region in a given technology $\mathrm{z}$ ([E(Nizt) $\mathrm{E}($ SpecRate $\left.\mathrm{zt})]^{\prime}\right)$ is a dummy variable that takes the value 1 if a given region $\mathrm{i}$ is specialized in $\mathrm{z}$, and 0 otherwise.

Step 3: Computation of number of specializations caused by existing differences between the $\underline{\text { technological structure of each region and the average technological structure prevailing in all }}$ $\underline{\text { regions }}$

$\operatorname{Dif}_{\text {it }}=\sum_{z=1}^{n}[\text { Nizt E }(\text { SpecRate zt })]^{\prime}-\mathrm{E}($ Specit $)$

such that:

$[$ Nizt E(SpecRate zt $)]^{\prime}=1$ if Nizt $E($ SpecRate $z t) \geq 1$

$[\text { Nizt } \mathrm{E}(\text { SpecRate } \mathrm{zt})]^{\prime}=0$ if Nizt $\mathrm{E}($ SpecRate $\mathrm{zt})<1$

where Dif $f_{\text {it }}$ represents the number of specializations in region $\mathrm{i}$ and year $\mathrm{t}$ that are attributed to difference existing between the technological structure of region $\mathrm{i}$ at $\mathrm{t}$, and the average technological structure prevailing in all regions in year $\mathrm{t}$.

Step 4: Computation of number of technology-adjusted specializations in each region i in year $\underline{\mathrm{t}}$

AdjustedSpec $_{\mathrm{it}}=\sum_{z=1}^{n}$ Specizt $-\mathrm{Dif}_{\mathrm{it}}$

such that:

$\mathrm{Spec}_{\mathrm{izt}}=1$ if $\mathrm{RCA}_{\mathrm{izt}}>1$ 
$\mathrm{Spec}_{\mathrm{izt}}=0$ if $\mathrm{RCA}_{\mathrm{izt}} \leq 1$

where AdjustedSpec ${ }_{i t}$ represents the total number of technology-adjusted specializations in region $\mathrm{i}$ and year $\mathrm{t}$, and $\mathrm{Spec}_{\mathrm{izt}}$ is dummy variable that reflects the specialization status of a given region $\mathrm{i}$ in technology $\mathrm{z}$ in year $\mathrm{t}$. It takes the value 1 if a given region $\mathrm{i}$ has RCA (Revealed Comparative Advantage) greater than 1, and 0 otherwise.

Step 5: Computation of the technology-adjusted diversification potential for each region i in year t

AdjustedDivPotential $_{\text {it }}=\mathrm{n}-$ AdjustedSpec $_{\text {it }}$

where AdjustedDivPotential $_{i t}$ is the sector-adjusted diversification potential of a given region $\mathrm{i}$ in year t. 


\section{Appendix C: Computation of control variables}

\section{- Technological diversity ${ }^{11}$}

To evaluate the existing technological diversity in a given region, this article proposes computing the inverse of the Herfindhal Index:

Diversity $_{i t}=\frac{1}{\sum_{z=1}^{n} \frac{\text { NiztNizt }}{\text { Nit Nit }}}$

where $\mathrm{N}$ represents the number of patents, the subscripts $\mathrm{i}, \mathrm{z}$ and $\mathrm{t}$ concern region $\mathrm{i}$, technology $\mathrm{z}$ and year $\mathrm{t}$, and $\mathrm{n}$ is the total number of technologies existing in the sample. Diversity $\mathrm{it}_{\mathrm{t}}$ represents the technological diversity of region $\mathrm{i}$ in year $\mathrm{t}$. As this work will conduct interregional comparisons over time, and the technological structures of the regions vary considerably, it is useful to normalize (12A) according to the following formula:

NormalizedDiversity ${ }_{\mathrm{it}}=\frac{\text { Diversityit }-1}{n-1}$

This normalization guarantees that the values for diversity index will always be within the range $[0,1]$, with 0 meaning no diversity at all, and 1 representing a perfectly diversified technological structure. Total diversity means that in region $\mathrm{i}$ and year $\mathrm{t}$, the total number of patents is equally distributed across all possible technological fields (n). Conversely, if diversity for region i and year $t$ takes the value 0 , then for that region all patents are concentrated just in one technological field. This analysis uses always the normalized version.

- EU support: Regional investments from the European Regional Development Fund (ERDF) and the Cohesion Fund (CF)

\footnotetext{
${ }^{11}$ Diversity is distinct from diversification. Whereas the latter is dynamic and evaluates to what extent new varieties emerge, the former is static and measures the existing variety of technologies within a regional technological system, at a given timepoint.
} 
DG Regio provides data on regional ERDF and CF investments 2000-2013. However, such data for each NUTS 2 are disaggregated not by year, but by programming period (2000-2006 and 2007-2013). Moreover, as noted in Ciffolilli et al. (2015) ${ }^{12}$ the best way to compare data from the two programming periods is to use investment commitments, not actual expenditures. ${ }^{13}$ Therefore, for each region ${ }^{14}$ and programming period it is collected data on investment commitments by category, ${ }^{15}$ as well as total investment commitments. As the sample covers the period 2000-2013, it is assumed that the EU regional investments from ERDF and CF from each programming period essentially affect a given region in those periods, in which most years coincide with the years included in a given programming period. Here this article assumes that the first five periods of the dataset are affected by the programming period 2000-2006, and the final five periods affected mainly by the programming period 2007-2013. Therefore, the data on EU regional investment commitments for a given region are timeinvariant for the first and last five periods included in the analysis. The only source of time variation can be found between the first five periods and the five last ones. As data on commitments are available only in nominal terms, this work follows Rodriguez-Pose \& Fratesi $(2004)^{16}$ and compute the percentage of such nominal commitments as a share of the cumulated GDP PPS at current market prices over each programming period.

\section{- Other controls: Eurostat regional statistics}

\footnotetext{
${ }^{12}$ Ciffolilli, A., Condello, S., Pompili, M. \& Roemisch, R. (2015). Geography of expenditure. Final report, Work Package 13: Ex post evaluation of Cohesion Policy programmes 2007-2013, focusing on the European Regional Development Fund (ERDF) and the Cohesion Fund (CF). Directorate-General for Regional and Urban Policy, European Commission

${ }^{13}$ This is because 2000-2006 expenditure data were not available, and payments were estimated using the absorption rates by country and fund. I believe that commitments can work as a good proxy for the total EU support received by a given region.

${ }^{14}$ For Denmark, only NUTS 1 data were available. NUTS 2 data were estimated by attributing to each region the same share of the funding by category as attributed for the programming period 2007-2013.

15 Business Support, Energy Environment and Natural Resources, Human Resources, IT Infrastructure and Services, Other, Research and Technology, Social Infrastructure, Technical Assistance, Tourism \& Culture, Transport Infrastructure, and Urban and Rural Regeneration

${ }^{16}$ Rodriguez-Pose, A. \& Fratesi, U. (2004). Between development and social policies: The Impact of European Structural Funds in Objective 1 Regions, Regional Studies, 38, 97-113
} 
Although it is possible to use Eurostat data directly, Eurostat Regional Statistics involve some missing values for several years in certain regions. To overcome this data shortcoming, whenever possible I compute missing values using one of the following procedures, in the following order:

- For a given NUTS 2 where data are missing for year $\mathrm{t}$, I compute the ratio between the value for the nearest year after $\mathrm{t}(\mathrm{t}+\mathrm{x})$ for which data are available at NUTS 2 level and the NUTS 1 value for that year $(\mathrm{t}+\mathrm{x})$. This ratio is then multiplied by the NUTS 1 value for the year $(\mathrm{t})$ for which NUTS 2 data are missing;

- For a given NUTS 2 where data are missing for year $\mathrm{t}$, I compute the ratio between the value for the nearest year after $t(t+x)$ for which data are available at NUTS 2 level and the NUTS 0 value for that year $(\mathrm{t}+\mathrm{x})$. This ratio is then multiplied by the NUTS 0 value for the year $(\mathrm{t})$ for which NUTS 2 data are missing;

- For a given NUTS 2 where data are for year $\mathrm{t}, \mathrm{I}$ attribute the same value as $\mathrm{t}-1$;

- For a given NUTS 2 where data are missing for $t, I$ attribute the same value as $t+1$;

- For a given NUTS 2 where data are missing for year $t$, I attribute the same value of the NUTS 1 to which the NUTS 2 belongs;

- For a given NUTS 2 where data are missing for year t, I attribute the same value of the NUTS 0 to which the NUTS 2 belongs 


\section{Appendix D: Correlation Matrix}

Table D1. Correlation Matrix

\begin{tabular}{|c|c|c|c|c|c|c|c|c|c|c|c|c|c|c|c|c|c|c|c|}
\hline \multirow[b]{2}{*}{$\mathrm{N}$ new specializ. } & \multicolumn{2}{|c|}{$\begin{array}{c}N \text { new } \\
\text { specializ. }\end{array}$} & \multicolumn{2}{|c|}{ Diversification } & \multicolumn{2}{|c|}{ CooperationWithin } & \multicolumn{2}{|c|}{ CooperationBetween } & \multicolumn{2}{|c|}{ Diversity } & \multicolumn{2}{|c|}{ EU rsupport } & \multicolumn{2}{|c|}{ Un_rate } & \multicolumn{2}{|c|}{ Tertiary_edu } & \multicolumn{2}{|c|}{ GDPpc } & \multirow[t]{2}{*}{$R \& D$} \\
\hline & 1.00 & & & & & & & & & & & & & & & & & & \\
\hline Diversification & 0.91 & $* * *$ & 1.00 & & & & & & & & & & & & & & & & \\
\hline CooperationWithin & $\begin{array}{c}- \\
0.13\end{array}$ & $* * *$ & -0.20 & $* * *$ & 1.00 & & & & & & & & & & & & & & \\
\hline CooperationBetween & $\begin{array}{c}- \\
0.19\end{array}$ & $* * *$ & -0.24 & $* * *$ & 0.07 & $* * *$ & 1.00 & & & & & & & & & & & & \\
\hline Diversity & 0.37 & $* * *$ & 0.47 & $* * *$ & -0.23 & $* * *$ & -0.22 & $* * *$ & 1.00 & & & & & & & & & & \\
\hline EU support & $\overline{-}-\overline{26}$ & $* * *$ & -0.33 & $* * *$ & 0.29 & $* * *$ & 0.18 & $* * *$ & -0.31 & $* * *$ & 1.00 & & & & & & & & \\
\hline Un_rate & $\overline{-}$ & $* * *$ & -0.20 & $* * *$ & 0.24 & $* * *$ & 0.19 & $* * *$ & -0.23 & $* * *$ & 0.28 & $* * *$ & 1.00 & & & & & & \\
\hline Tertiary_edu & 0.20 & $* * *$ & 0.25 & $* * *$ & -0.22 & $* * *$ & -0.12 & $* * *$ & 0.11 & $* * *$ & -0.30 & $* * *$ & -0.17 & $* * *$ & 1.00 & & & & \\
\hline GDPpc & 0.22 & $* * *$ & 0.33 & $* * *$ & -0.30 & $* * *$ & -0.19 & $* * *$ & 0.29 & $* * *$ & -0.44 & $* * *$ & -0.42 & $* * *$ & 0.51 & $* * *$ & 1.00 & & \\
\hline$R \& D$ & 0.17 & $* * *$ & 0.29 & $* * *$ & -0.25 & $* * *$ & -0.15 & $* * *$ & 0.20 & $* * *$ & -0.30 & $* * *$ & -0.20 & $* * *$ & 0.41 & $* * *$ & 0.40 & $* * *$ & 1.00 \\
\hline
\end{tabular}

$* p<0.1,{ }^{* *} p<0.05, * * * p<0.01$

Source: author's computations 


\section{Appendix E: Comparison of the Difference GMM estimation results for different number of instruments}

Table E1. Estimation results -Difference GMM using all suitable lags as instruments and Difference GMM using only second lag instruments

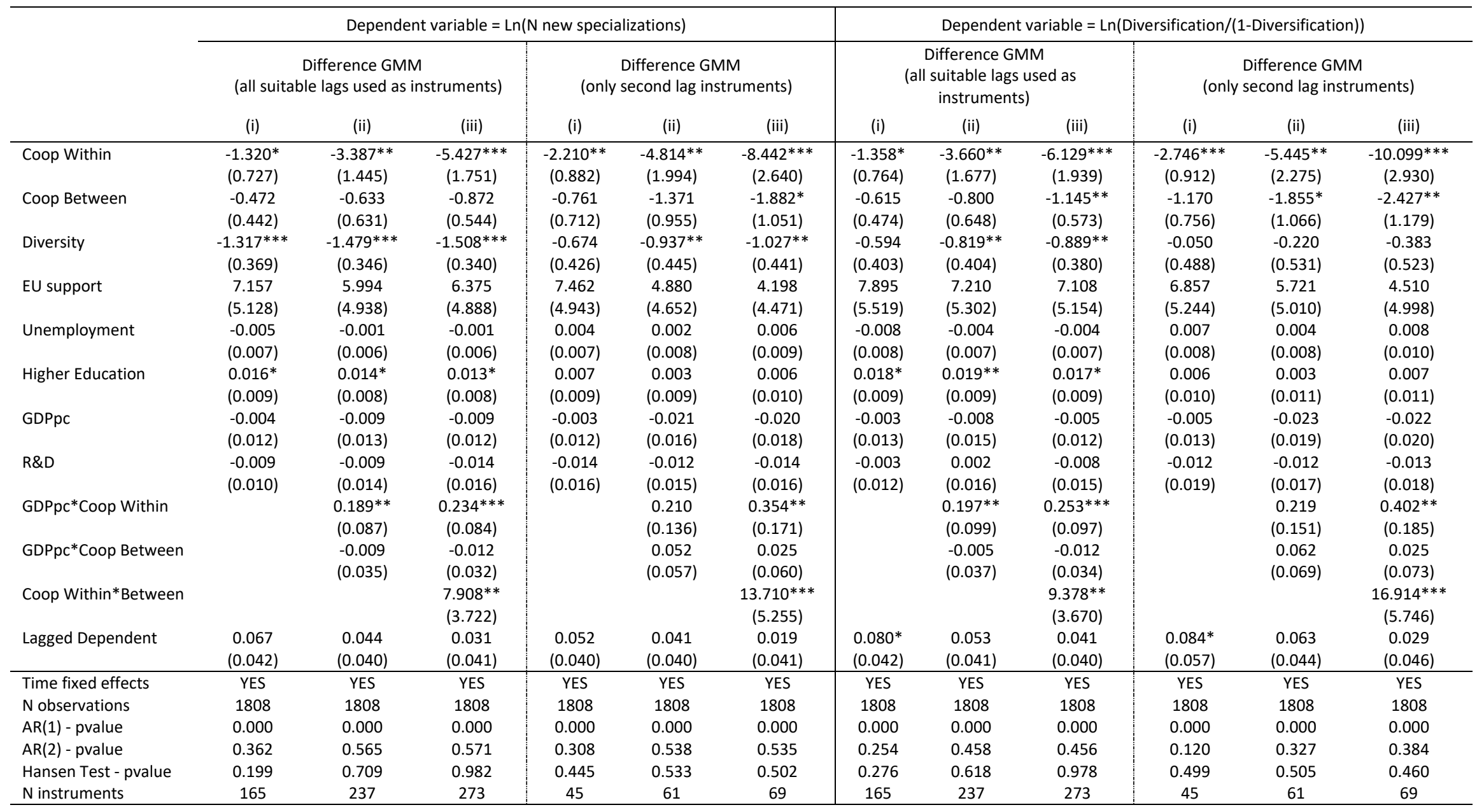

${ }^{*} p<0.1,{ }^{* *} p<0.05, * * * p<0.01$

Source: author's computations 
Table E2. Marginal effects of cooperation within regions and between regions, on the dependent variable, for differing levels of GDPpc

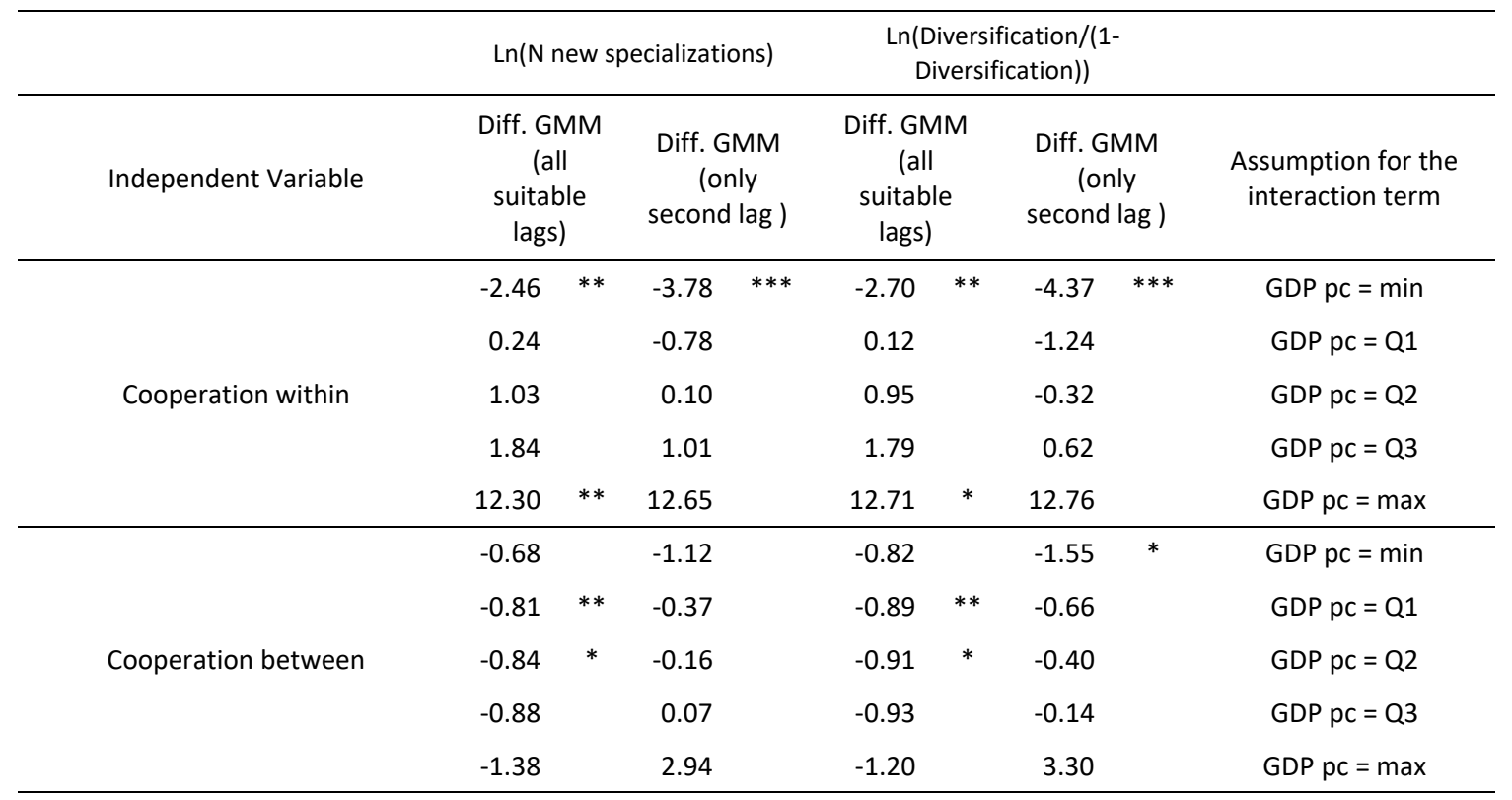

$* p<0.1, * * p<0.05, * * * p<0.01$

Source: author's computations 
Table E3. Marginal effects of cooperation within regions and between regions, on the dependent variable, for differing levels of interaction terms

\begin{tabular}{|c|c|c|c|c|c|c|c|c|c|c|}
\hline \multirow{3}{*}{ Independent Variable } & \multicolumn{4}{|c|}{ Ln(N new specializations) } & \multicolumn{4}{|c|}{$\begin{array}{l}\text { Ln(Diversification/(1- } \\
\text { Diversification)) }\end{array}$} & & \\
\hline & \multicolumn{2}{|c|}{$\begin{array}{c}\text { Diff. GMM } \\
\text { (all } \\
\text { suitable } \\
\text { lags) }\end{array}$} & \multicolumn{2}{|c|}{$\begin{array}{l}\text { Diff. GMM } \\
\text { (only } \\
\text { second lag ) }\end{array}$} & \multicolumn{2}{|c|}{$\begin{array}{c}\text { Diff. GMM } \\
\text { (all } \\
\text { suitable } \\
\text { lags) }\end{array}$} & \multicolumn{2}{|c|}{$\begin{array}{l}\text { Diff. GMM } \\
\text { (only } \\
\text { second lag ) }\end{array}$} & \multicolumn{2}{|c|}{$\begin{array}{l}\text { Assumption for the } \\
\text { interaction terms }\end{array}$} \\
\hline & -4.28 & $* * *$ & -6.71 & $* * *$ & -4.89 & $* * *$ & -8.13 & $* * *$ & $\mathrm{GDP} p \mathrm{p}=\min$ & \\
\hline \multirow{4}{*}{ Cooperation within } & -0.93 & & -1.65 & & -1.27 & & -2.37 & & $\mathrm{GDP} p \mathrm{c}=\mathrm{Q1}$ & Cooperati \\
\hline & 0.05 & & -0.17 & & -0.20 & & -0.68 & & $\mathrm{GDP} p \mathrm{c}=\mathrm{Q} 2$ & $\begin{array}{c}\text { on } \\
\text { between }=\end{array}$ \\
\hline & 1.06 & & 1.351 & & 0.88 & & 1.05 & & $\mathrm{GDP} p \mathrm{c}=\mathrm{Q} 3$ & $\min$ \\
\hline & 14.03 & $* *$ & 20.94 & $*$ & 14.92 & $* *$ & 23.35 & $*$ & GDP $p c=\max$ & \\
\hline \multirow{5}{*}{ Cooperation within } & -3.32 & $* * *$ & -5.04 & $* * *$ & -3.74 & $* * *$ & -6.06 & $* * *$ & $\mathrm{GDP} p \mathrm{c}=\min$ & \\
\hline & 0.03 & & 0.018 & & -0.12 & & -0.31 & & $\mathrm{GDP} p \mathrm{c}=\mathrm{Q1}$ & Cooperati \\
\hline & 1.02 & & 1.503 & & 0.94 & & 1.382 & & $\mathrm{GDP} p \mathrm{c}=\mathrm{Q} 2$ & $\begin{array}{c}\text { on } \\
\text { between }=\end{array}$ \\
\hline & 2.02 & $*$ & 3.023 & & 2.03 & & 3.113 & & $\mathrm{GDP} p \mathrm{c}=\mathrm{Q} 3$ & Q2 \\
\hline & 15.00 & $* * *$ & 22.61 & $*$ & 16.06 & $* *$ & 25.42 & * & $\mathrm{GDP} p \mathrm{c}=\max$ & \\
\hline \multirow{5}{*}{ Cooperation within } & 2.26 & & 4.636 & & 2.87 & $*$ & 5.87 & $*$ & $\mathrm{GDP} p c=\min$ & \multirow{5}{*}{$\begin{array}{c}\text { Cooperati } \\
\text { on } \\
\text { between }= \\
\max \end{array}$} \\
\hline & 5.61 & $* *$ & 9.691 & $* *$ & 6.49 & $* *$ & 11.63 & $* *$ & $\mathrm{GDP} p \mathrm{c}=\mathrm{Q} 1$ & \\
\hline & 6.60 & $* *$ & 11.18 & $* *$ & 7.56 & $* * *$ & 13.32 & $* *$ & $\mathrm{GDP} p \mathrm{c}=\mathrm{Q} 2$ & \\
\hline & 7.60 & $* * *$ & 12.7 & $* *$ & 8.65 & $* * *$ & 15.05 & $* *$ & $\mathrm{GDP} p \mathrm{c}=\mathrm{Q3}$ & \\
\hline & 20.58 & $* * *$ & 32.29 & $* *$ & 22.68 & $* * *$ & 37.35 & $* *$ & GDP $p c=\max$ & \\
\hline \multirow{5}{*}{ Cooperation between } & 0.27 & & -0.15 & & 0.10 & & -0.45 & & $\mathrm{GDP} p \mathrm{c}=\min$ & \multirow{5}{*}{$\begin{array}{l}\text { Cooperati } \\
\text { on within } \\
=\text { min }\end{array}$} \\
\hline & 3.62 & $* *$ & 4.906 & & 3.72 & $*$ & 5.301 & & $\mathrm{GDP} p \mathrm{c}=\mathrm{Q} 1$ & \\
\hline & 4.61 & $* *$ & 6.39 & $*$ & 4.78 & $* *$ & 6.991 & $*$ & $\mathrm{GDP} p \mathrm{c}=\mathrm{Q} 2$ & \\
\hline & 5.61 & $* *$ & 7.911 & $*$ & 5.87 & $* *$ & 8.722 & $*$ & $\mathrm{GDP} p \mathrm{c}=\mathrm{Q} 3$ & \\
\hline & 18.59 & $* * *$ & 27.5 & $* *$ & 19.90 & $* *$ & 31.02 & $* *$ & GDP $p c=\max$ & \\
\hline \multirow{5}{*}{ Cooperation between } & 0.53 & & 0.288 & & 0.40 & & 0.086 & & $\mathrm{GDP} p \mathrm{c}=\min$ & \multirow{5}{*}{$\begin{array}{c}\text { Cooperati } \\
\text { on within } \\
\text { = Q2 }\end{array}$} \\
\hline & 3.88 & $* *$ & 5.344 & $*$ & 4.02 & $* *$ & 5.841 & $*$ & $\mathrm{GDP} p \mathrm{c}=\mathrm{Q} 1$ & \\
\hline & 4.86 & $* *$ & 6.829 & $*$ & 5.08 & $* *$ & 7.532 & $*$ & $\mathrm{GDP} p \mathrm{c}=\mathrm{Q} 2$ & \\
\hline & 5.87 & $* *$ & 8.349 & $*$ & 6.17 & $* *$ & 9.262 & $*$ & $\mathrm{GDP} p \mathrm{c}=\mathrm{Q3}$ & \\
\hline & 18.84 & $* * *$ & 27.94 & $* *$ & 20.20 & $* *$ & 31.56 & $* *$ & GDP $p c=\max$ & \\
\hline \multirow{5}{*}{ Cooperation between } & 4.23 & $* *$ & 6.705 & $* *$ & 4.79 & $* *$ & 8.002 & $* *$ & $\mathrm{GDP} p \mathrm{c}=\min$ & \multirow{5}{*}{$\begin{array}{l}\text { Cooperat } \\
\text { on within } \\
=\max \end{array}$} \\
\hline & 7.58 & $* * *$ & 11.76 & $* *$ & 8.41 & $* * *$ & 13.76 & $* *$ & $\mathrm{GDP} p \mathrm{c}=\mathrm{Q1}$ & \\
\hline & 8.56 & $* * *$ & 13.25 & $* *$ & 9.47 & $* * *$ & 15.45 & $* *$ & $\mathrm{GDP} p \mathrm{c}=\mathrm{Q} 2$ & \\
\hline & 9.57 & $* * *$ & 14.77 & $* *$ & 10.56 & $* * *$ & 17.18 & $* *$ & $\mathrm{GDP} p \mathrm{c}=\mathrm{Q3}$ & \\
\hline & 22.54 & $* * *$ & 34.36 & $* *$ & 24.59 & $* * *$ & 39.48 & $* *$ & $\mathrm{GDP} p \mathrm{pc}=\max$ & \\
\hline
\end{tabular}

${ }^{*} p<0.1,{ }^{* *} p<0.05,{ }^{* * *} p<0.01$

Source: author's computations 